\title{
Mutations in a barley cytochrome P450 gene enhances pathogen induced programmed cell death and cutin layer instability
}

\author{
Gazala Ameen $\oplus^{1}$, Shyam Solanki $\oplus^{1}$, Lauren Sager-Bittara ${ }^{2}$, Jonathan Richards $\oplus^{3}$, \\ Prabin Tamang $\oplus^{4}$, Timothy L. Friesen $\oplus^{5}$, Robert S. Brueggeman ${ }^{6 *}$
}

1 Department of Agronomy, Horticulture \& Plant Science, South Dakota State University, Brookings, South Dakota, United States of America, 2 Department of Plant Pathology, North Dakota State University, Fargo, North Dakota, United States of America, 3 Department of Plant Pathology and Crop Physiology, Louisiana State University Agricultural Center, Baton Rouge, Louisiana, United States of America, 4 USDA-ARS, Natural Products Utilization Research Unit, Oxford, Mississippi, United States of America, 5 USDA-ARS, Red River Valley Agricultural Research Center, Cereal Crops Research Unit, Fargo, North Dakota, United States of America, 6 Department of Crop and Soil Sciences, Washington State University, Pullman, Washington, United States of America

* Bob.Brueggeman@wsu.edu

\section{G openaccess}

Citation: Ameen G, Solanki S, Sager-Bittara L, Richards J, Tamang P, Friesen TL, et al. (2021) Mutations in a barley cytochrome P450 gene enhances pathogen induced programmed cell death and cutin layer instability. PLoS Genet 17(12): e1009473. https://doi.org/10.1371/journal. pgen.1009473

Editor: Gitta Coaker, University of California Davis, UNITED STATES

Received: March 5, 2021

Accepted: November 26, 2021

Published: December 16, 2021

Copyright: This is an open access article, free of all copyright, and may be freely reproduced, distributed, transmitted, modified, built upon, or otherwise used by anyone for any lawful purpose. The work is made available under the Creative Commons CCO public domain dedication.

Data Availability Statement: GenBank Bio project PRJNA666939 has the RNAseq data completely submitted and freely available. Exome capture of WT Steptoe and the allelic mutants nec3.I and nec3.m NCBI submission BioSample accessions SAMN22109510, SAMN22109511, SAMN22109512.

Funding: The author(s) received no specific funding for this work.

\section{Abstract}

Disease lesion mimic mutants (DLMMs) are characterized by the spontaneous development of necrotic spots with various phenotypes designated as necrotic (nec) mutants in barley. The nec mutants were traditionally considered to have aberrant regulation of programmed cell death (PCD) pathways, which have roles in plant immunity and development. Most barley nec3 mutants express cream to orange necrotic lesions contrasting them from typical spontaneous DLMMs that develop dark pigmented lesions indicative of serotonin/phenolics deposition. Barley nec3 mutants grown under sterile conditions did not exhibit necrotic phenotypes until inoculated with adapted pathogens, suggesting that they are not typical DLMMs. The $\mathrm{F}_{2}$ progeny of a cross between nec3- $\mathrm{\gamma} 1$ and variety Quest segregated as a single recessive susceptibility gene post-inoculation with Bipolaris sorokiniana, the causal agent of the disease spot blotch. Nec3 was genetically delimited to $0.14 \mathrm{cM}$ representing 16.5 megabases of physical sequence containing 149 annotated high confidence genes. RNAseq and comparative analysis of the wild type and five independent nec3 mutants identified a single candidate cytochrome P450 gene (HORVU.MOREX.r2.6HG0460850) that was validated as nec 3 by independent mutations that result in predicted nonfunctional proteins. Histology studies determined that nec 3 mutants had an unstable cutin layer that disrupted normal Bipolaris sorokiniana germ tube development.

\section{Author summary}

At the site of pathogen infection, plant defense mechanisms rely on controlled programmed cell death (PCD) to sequester biotrophic pathogens that require living cells to extract nutrients from the host. However, these defense mechanisms are hijacked by 
Competing interests: The authors have declared that no competing interests exist. necrotrophic plant pathogens that purposefully induce PCD to feed on the dead cells, thus facilitating further disease development. Thus, understanding PCD responses is important for resistance to both classes of pathogens. We characterized five independent disease lesion mimic mutants of barley designated necrotic 3 (nec3) that show aberrant regulation of PCD responses upon pathogen challenge. A cytochrome $\mathrm{P} 450$ gene was identified as Nec3 encoding a Tryptamine 5-Hydroxylase that functions as a terminal serotonin biosynthetic enzyme in the Tryptophan pathway of plants. We posit that nec3 mutants have disrupted serotonin biosynthesis resulting in expanded $\mathrm{PCD}$, necrotrophic pathogen susceptibility and cutin layer instability. The nec 3 mutants show expanded PCD and disease susceptibility of pathogen-induced necrotic lesions, suggesting a role of serotonin to sequester PCD and suppress pathogen colonization. The identification of Nec3 will facilitate functional analysis to elucidate the role that serotonin plays in the elicitation or suppression of PCD immunity responses to diverse pathogens and the effects it has on cutin layer biosynthesis.

\section{Introduction}

Programmed cell death (PCD) is a highly evolved and tightly regulated physiological response of plant and animal cells that plays a role in development, cell differentiation, cell number homeostasis, and immunity [1]. In plants, PCD is activated by environmental cues, including biotic stress-induced by pathogens and represents the major physiological response and mechanism of defense against invading microbes or feeding invertebrates. Specialized or adapted plant pathogens evolved to produce and utilize virulence effectors to facilitate host penetration and colonization by manipulating the host cellular machinery to induce inappropriate physiological responses that promote access to nutrients and life cycle completion [2].

The plant's innate immune system evolves transmembrane receptors known as pattern recognition receptors (PRRs) that detect invading pathogens in the apoplastic space as the first line of defense and is known as pathogen-associated molecular patterns (PAMP) triggered immunity (PTI). The PTI responses activate underlying cytosolic signaling cascades, including the mitogen-activated protein kinase (MAPK) pathways [3] inducing callose deposition at the point of pathogen penetration, expression of pathogenesis-related (PR) genes, a quick transient reactive oxygen species (ROS), hypersensitive response (HR), and in most responses the resulting necrotic lesions at the site of attempted pathogen penetration is accompanied by the deposition of phenolic compounds. The selective pressures exerted by pathogens forced plant innate immune systems to counter-evolve to recognize pathogen virulence effectors [4-7] and more commonly their manipulation of targeted host proteins [8]. A well-characterized example is the Pseudomonas syringae effectors that inhibit FLS2 PRR-mediated signaling following flg22 perception [9]. For biotrophic pathogens, that require living host cells to feed, these effectors no longer facilitate colonization but rather alert the host to their presence, eliciting PCD that kills the cells they are feeding on, effectively stopping the colonization process. Thus, HR is critical to plant innate immunity against biotrophic plant pathogens, including viruses, bacteria, fungi, oomycetes, and invertebrates [10]. However, the necrotrophic pathogens that acquire nutrients from dying cells such as Parastagonospora nodorum [11] and Pyrenophora teres [12] have adapted to hijack these gene-for-gene immunity mechanisms by evolving necrotrophic effectors (NEs) that purposely alert the host immune system of their presence through immunity receptor activation. These inverse-gene-for-gene interactions [13] initiate PCD responses, which the necrotrophic pathogens utilize to facilitate disease formation 
because they acquire nutrients from the resulting dying and dead tissues. Thus, necrotrophic pathogens can complete their lifecycle on the host by facilitating further disease development through necrotrophic effector-triggered susceptibility (NETS); [12]. Both biotrophic and necrotrophic pathogens elicit PCD immunity responses in plants with different outcomes, incompatibility-vs- compatibility, respectively, determined by the lifestyle of the pathogen and the timing of the responses. Thus, knowledge of PCD pathways is important to understand resistance and susceptibility mechanisms in crop plants when interacting with both classes of pathogens.

The disease lesion mimic mutants (DLMMs) that spontaneously produce PCD are important resources to decipher the regulation of the cell death pathways [14]. However, very few DLMMs have been thoroughly characterized. In barley, several DLMMs have been described [14], but only two DLMM genes have been identified, Hvnecl and mlo. The Hvnecl gene encodes a cyclic-gated ion channel protein $[15,16]$ with sequence homology to the Arabidopsis thaliana HLM1 gene [17]. Like HLM1, Hvnec1 has increased pathogenesis-related (PR) protein expression and produces spontaneous necrotic lesions and leaf tip necrosis with increased susceptibility to certain pathogens $[18,19]$. The mlo gene, which confers increased resistance to the fungal pathogen Erysiphe graminis f. sp. hordei, the causal agent of powdery mildew, has been deployed in Northern Europe and has served as a source of durable resistance in barley for 37 years [20]. However, in the absence of the disease, mlo causes $\sim 4 \%$ reduction in yield due to its DLMM phenotype, which results in loss of photosynthetic potential and thus is only economically advantageous under high disease pressure [21]. The second cost of mlo deployment is enhanced susceptibility to several necrotrophic pathogens, including Bipolaris sorokiniana the causal agent of the barley disease spot blotch [22], Fusarium graminearum the cause of fusarium head blight [23], Ramularia collo-cygni the causal agent of Ramularia leaf spot [24] and Magnaporthe oryzae the causal agent of the rice blast disease [25]. The Mlo gene encodes a ROP like G-protein that appears to be a suppressor of PCD and is conserved and found in other species, including pea, Arabidopsis and tomato [25].

In barley, both chemical and irradiation mutagenesis have been utilized to induce a large collection of DLMMs [26]. One DLMM mutant was designated as nec3 and was shown to produce distinct cream to orange necrotic lesions (Fig 1). The nec3- $\gamma 1$ mutant described here was originally identified from $\gamma$-irradiated $\mathrm{M}_{2}$ seedlings in an attempt to identify barley mutants resistant to B. sorokiniana isolate ND90Pr. This study was initiated to identify mutants in a putative cv Bowman dominant susceptibility factor [27]. The previously identified nec3 mutants were irradiated using $\mathrm{x}$-ray mutagenesis in the cv Proctor and Villa backgrounds and by fast neutron mutagenesis in the cv Steptoe background [28]. The nec3.d (GSHO 1330) mutant was generated in cv Proctor (PI 280420) and the nec3.e (GSHO 2423) mutant was generated in cv Villa (PI 399506). The nec3.l (GSHO 3605 formally known as FN362) and nec3.m (GSHO 3606 formally known as FN363) mutants were generated in the cv Steptoe (CIho 15229) background. The nec3. $d$ and nec3.e mutants used in this study were near isogenic lines developed by recurrent backcrossing into the cv Bowman background. Four of the five allelic nec3 mutants express a distinctive programmed cell death phenotype with tan to orange necrotic lesions without the dark phenolics usually associated with DLMMs. The previous attempt to identify nec3 utilizing morphological markers localized nec 3 to the centromeric region of barley chromosome $6 \mathrm{HS} \sim 29.2 \mathrm{cM}$ distal of the rob 1 (orange lemma 1) locus $[26,29,30]$.

In this study genetic mapping and RNAseq-based gene structure identification among the WT and mutants identified the candidate Nec3 gene (HORVU.MOREX.r2.6HG0460850), which was predicted to encode a Cytochrome P450, designated as HvCYP71-A1. Allele analysis of five independent nec3 mutants identified five different mutations that were detrimental to 
$H v C Y P 71-A 1$ function, validating it as Nec3. We report that Nec3 putatively encodes a tryptamine 5-hydroxylase, which catalyzes the conversion of tryptamine to serotonin, similar to the rice lesion mimic phenotype producing $S L$ gene [31,32]. In addition, we show that the nec 3 phenotype is not a spontaneous DLMM but is rather induced by several species of Ascomycete pathogenic fungi, both necrotrophs and biotrophs and the bacterial pathogen Xanthomonas translucens, representing pathogens that penetrate the host cells directly by disrupting the cell wall and plasma membrane. We also determined that the nec 3 mutants have an unstable cutin layer that possibly peels away from the leaf surface when in contact with the pathogen Bipolaris sorokinina germ tubes. This aberrant interaction possibly alters the pathogen's developmental signaling resulting in profuse branching of the fungal germ tubes on the mutant leaf surface. Our study will facilitate further $\mathrm{Nec} 3$ functional analysis and the roles it plays in the elicitation or suppression of PCD responses to diverse pathogens and the effects it has on cutin layer biosynthesis.

\section{Results}

\section{Pathogen induction of the nec 3 phenotype}

The nec 3 lesions consistently occurred on the five independent nec 3 mutants under normal greenhouse conditions even without pathogen challenge and were presumed to be lesion mimic mutants with spontaneous lesion development. To test the hypothesis that the nec 3 lesions were spontaneous, the wildtype and mutant plants were grown in a sterile isolation box. These plants did not express the nec 3 phenotype and grew to the adult plant stage (Feekes 10.5; full head emergence) without showing any necrotic lesions. The non-inoculated nec3 seedlings grown on the greenhouse bench outside the isolation box exhibited the nec 3 phenotype at the second leaf stage and continued to develop these distinctive lesions (Fig 1) through the adult plant stages. Histological characterization of the fungal structures that grew from the lesions of the non-inoculated nec 3 plants showed that they were primarily colonized by Blumeria graminis, which is endemic in the greenhouses at Washington State University and North Dakota State University, where these experiments were conducted.

To determine if the pathogen-induced nec 3 phenotypes were dependent on pathogen infection, we challenged wildtype and mutant plants with several different pathogens with both virulent and avirulent responses on wildtype Bowman or Steptoe plants. Inoculations performed under sterile environmental conditions in growth chambers determined that the typical nec3 lesions were elicited on nec3- $\gamma 1$ mutant seedlings by the necrotrophic ascomycete fungal

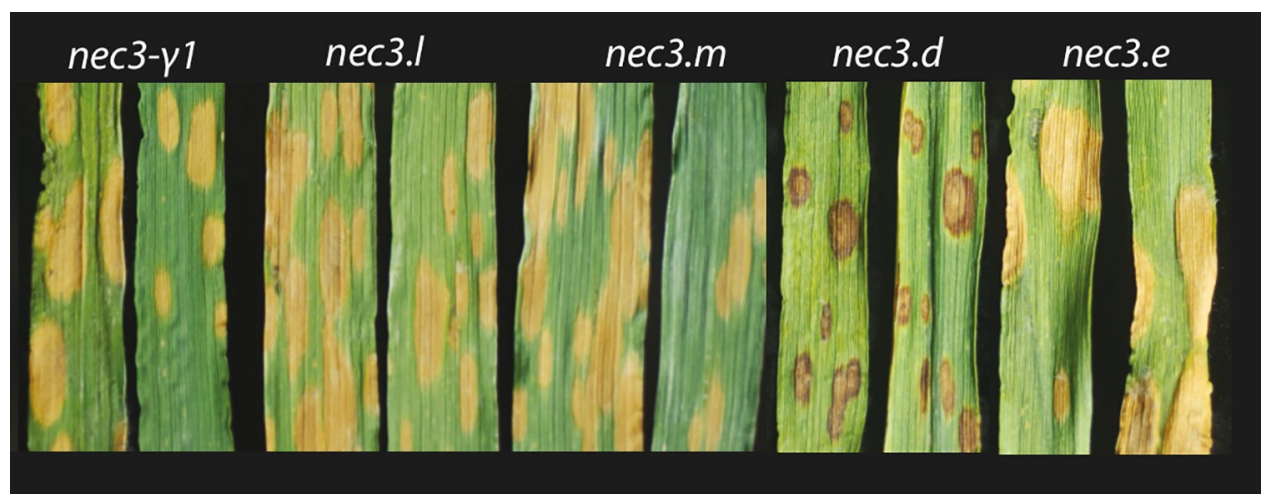

Fig 1. Typical phenotypic reactions of the nec3 mutants. The nec3 mutants are shown from left to right (nec3- $\gamma 1$, nec3.1, nec3.m, nec3.d and nec3.e) after infection with Bipolaris sorokiniana isolate ND85F.

https://doi.org/10.1371/journal.pgen.1009473.g001 


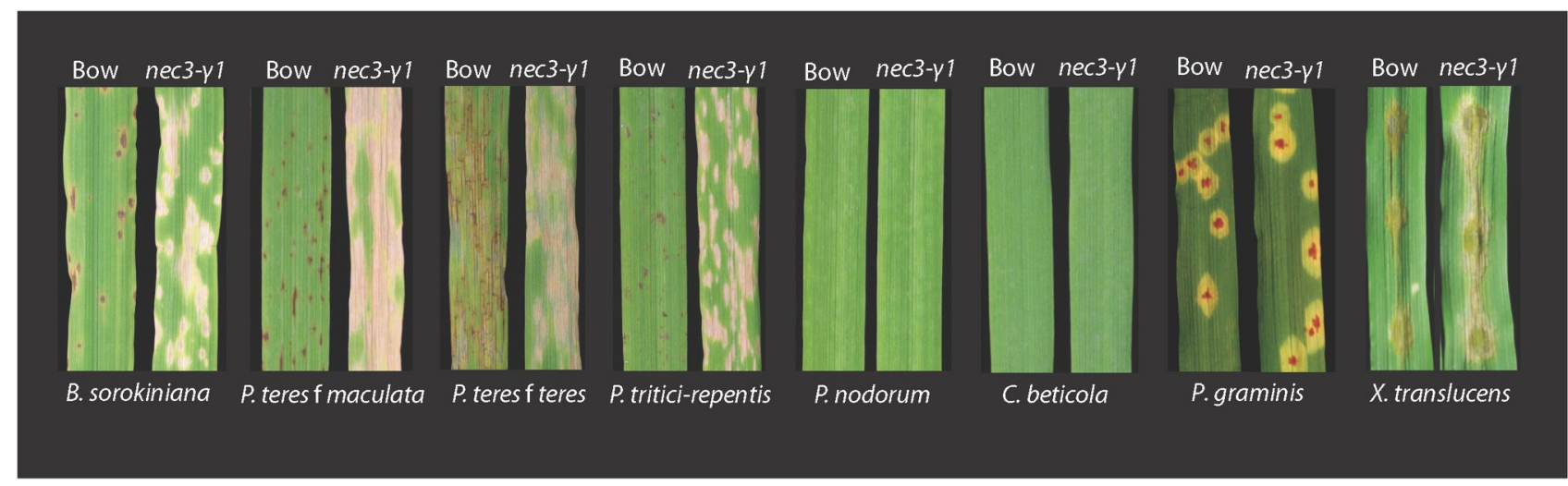

Fig 2. The nec3 phenotype was induced by Bipolaris sorokiniana, Pyrenophora teres f. teres, Pyrenophora teres f. maculata, Pyrenophora tritici repentis, and Xanthomonas translucens pv undulosa. Each panel shows the typical reaction to the pathogen labelled below with wildtype Bowman (Bow) on the left and the nec3- $\gamma 1$ mutant on the right as labeled above. Inoculations with Puccinia graminis f. sp. tritici race QCCJB, Cercospora beticola and Parastagonospora nodorum did not induce the nec3 phenotype.

https://doi.org/10.1371/journal.pgen.1009473.g002

pathogens Bipolaris sorokiniana, Pyrenophora teres $\mathrm{f}$. teres, Pyrenophora teres f. maculata, and Pyrenophora tritici repentis, as well as the biotrophic ascomycete fungal pathogen Blumeria graminis (Fig 2; Blumeria graminis inoculated plants are not shown). Both the virulent and avirulent isolates of these pathogens produced the expected susceptible or resistant response on wildtype Bowman or Steptoe but induced the typical nec3 lesions on the nec3- $\gamma 1$ mutant. Infiltration inoculations with the bacterial pathogen Xanthomonas translucens pv undulosa, which resulted in a resistant reaction on Bowman wildtype, also induced the nec3 phenotype on the nec3- $\gamma 1$ mutant (Fig 2). The nec3 phenotype was not induced when nec3- $\gamma 1$ mutant seedlings were inoculated with the basidiomycete biotrophic fungal pathogen Puccinia graminis f. sp. tritici race QCCJB that is virulent on cv Bowman, which carries the Rpg1 stem rust resistance gene (Fig 2). The nec3 phenotype was also not induced when nec3- $\gamma 1$ mutant seedlings were inoculated with $P$. graminis $\mathrm{f}$. sp. tritici race HKHJC that is avirulent on cv Bowman due to resistance provided by Rpg1 (Picture not shown). The barley non-host necrotrophic pathogens Cercospora beticola and Parastagonospora nodorum did not induces the nec3 phenotype.

\section{Allelism crosses}

Allelism crosses were performed in the field to determine if the four confirmed nec 3 mutants, nec3.d, nec3.e, nec3.1, and nec3.m were allelic to nec3- $\gamma 1$. Crosses between nec3- $\gamma 1$ and the mutants, nec3.d, nec3.e and nec3.l e were successful but due to the head sterility effect of the nec 3 mutants, only $2-5 \mathrm{~F}_{1}$ seeds were planted from each allelism test cross. $100 \%$ of the $\mathrm{F}_{1}$ plants displayed the nec3 phenotype following inoculation with B. sorokiniana isolate ND85F under greenhouse conditions (Fig 3). The isolate ND85F of B. sorokiniana used in this study is pathotype 1 (Steptoe and Proctor are susceptible and Bowman and Villa are resistant) which has been widely used in spot blotch association and bi-parental mapping. The $\mathrm{F}_{2}$ seed of each cross was planted in the field in rows containing 20 individual $F_{2}$ plants adjacent to a spot blotch disease nursery containing spreader rows inoculated with $B$. sorokiniana isolate ND85F. $100 \%$ of the $\mathrm{F}_{2}$ individuals exhibited the nec 3 phenotype (Fig 3) demonstrating that the nec3- $\gamma 1$ mutation was allelic to the other known nec3 mutants. Interestingly, the allelism cross (nec3. $d \times$ nec3- $\gamma 1$ ) with the nec3. $d$ mutant, which expresses dark lesions typical of phenolics build up and are smaller in size compared to the other nec 3 mutants, produced $\mathrm{F}_{2}$ progeny 


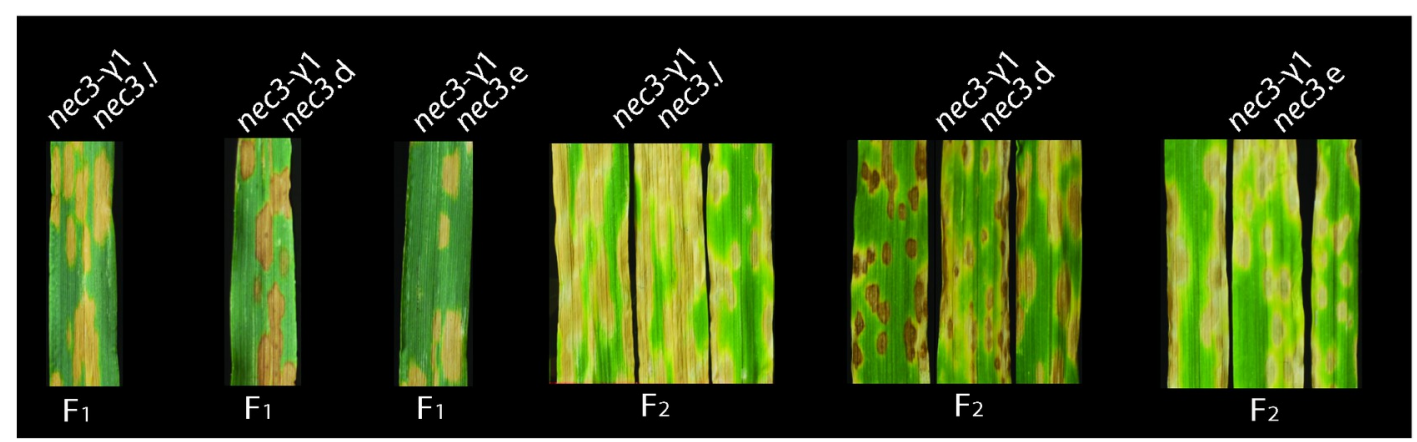

Fig 3. The typical phenotypes of the $F_{1}$ and $F_{2}$ progeny of nec 3 allelism tests. The first three panels show the phenotype of $F_{1}$ progeny of the nec3 mutants from allelic test crosses after infection with Bipolaris sorokiniana isolate ND85F. The progeny from the allelism test crosses were advanced to the $\mathrm{F}_{2}$ generation and assayed for the nec 3 phenotype post B. sorokiniana isolate ND85F inoculation. The allelism test crosses are shown above and generations shown below.

https://doi.org/10.1371/journal.pgen.1009473.g003

that expressed a range of lesion phenotypes, from the typical nec3.d to the nec3. $\gamma 1$ phenotype and a blending of both (Fig 3). These results suggested that the segregation of the two nec3 alleles had a blending effect on the lesion phenotypes.

\section{Culture filtrate infiltration}

A culture infiltration experiment was used to determine if the nec3 elicitor was present and if it is proteinaceous. The WT Bowman (resistant to isolate ND85F) and WT Steptoe (susceptible to isolate ND85F) and the nec3 mutants nec3- $\gamma 1$, nec3.d and nec3.e in the Bowman background and $n e c 3 . l$ and nec3.m in the Steptoe background showed differential reactions after infiltration with B. sorokiniana isolate ND85F culture filtrates and controls infiltrated into secondary leaves (S1 Fig). The infiltrations containing culture filtrates + Fries Media, culture filtrates + MOPS buffer, and culture filtrates + MOPS + pronase on the mutants nec3- $\gamma 1$, nec3.d, nec3. $e$, nec3.l and nec3.m showed typical nec3 PCD as previously described with a lack of defined margins around the lesions (S1 Fig). The control infiltrations containing Fries Media + MOPS buffer + pronase did not induce a reaction on the mutants or WT leaves. The WT Bowman leaves showed no response to any of the infiltrations, culture filtrates or control. However, the WT Steptoe seedlings displayed a PCD response to all the infiltrations containing culture filtrates that were different than nec3.l and nec3.m, the nec3 mutants in the Steptoe background. Steptoe reacted to the culture filtrates by forming necrotic lesions with dark margins and a dark necrotic center, which resembled susceptible lesions that are typically induced by the necrotrophic pathogen B. sorokiniana that contain phenolics accumulation.

\section{Exogenous supplementation of DAMPs, and PAMPs and supplementation with Serotonin and Tryptamine}

To determine if known DAMPs or PAMPs elicit the nec3 phenotype infiltrations with a known DAMP and PAMPs was performed. Infiltrations of WT Bowman, nec3- $\gamma 1$, WT Steptoe and nec3.l with the known DAMP trigalacturonic acid was carried out at three concentrations $(10 \mathrm{mg} / \mathrm{mL}, 1 \mathrm{mg} / \mathrm{mL}$ and $0.1 \mathrm{mg} / \mathrm{mL})$; the bacterial PAMP FLG22 at a concentration of $1 \mathrm{mg} /$ $\mathrm{mL}$ and chitin (C9752, Sigma-aldrich) $(100 \mu \mathrm{g} / \mathrm{ml})$ resulted in no observable reactions up to one week after infiltration (S2 Fig), as compared to the mock controls treated with water. To determine if Serotonin or Tryptamine accumulation effects the nec 3 phenotype an exogenous root feeding experiment was conducted. Exogenous root feeding of Serotonin and Tryptamine did produce visible phenotypic variance in the size and shape of nec3 lesions in nec3- $\gamma 1$, nec3. 
d, nec3.e, nec3.l and nec3.m mutants at seven days after pathogen inoculations compared to the mock controls treated with water. We observed that the Serotonin fed nec 3 mutants and wildtype plants displayed relatively reduced-sized disease lesions and show no observed chlorosis on the secondary leaf (S3A and S3B Fig). However, an opposite trend was observed in the tryptamine-fed plants, where the lesion size was relatively increased (S3A and S3B Fig).

\section{DAB staining and electron microscopy}

As the nec3 lesions expand more rapidly and are larger than those of the WT genotypes it was expected that the mutants would express differential ROS production. DAB staining associated with most of the B. sorokiniana penetration sites was observed as early as $12 \mathrm{hpi}$ on nec3- $\gamma 1$ inoculated leaves (Fig 4). The DAB staining associated with pathogen penetration sites was only observed in the resistant WT Bowman line after $18 \mathrm{hpi}$. During the later time-points (24$36 \mathrm{hpi}$ ) the DAB staining associated with B. sorokiniana penetration and colonization in the susceptible nec3- $\gamma 1$ mutant, rapidly increased to neighboring host epidermal cells, as well as underlying mesophyll cells. However, in the resistant WT Bowman seedlings, the DAB staining that started to appear at $\sim 24$ hpi had a higher intensity but remained limited to a few cells adjacent to the penetration site and did not expand at the later time-points during the infection process as was observed with the nec3- $\gamma 1$ mutant (Fig 4)

Time course light microscopy following DAB staining post B. sorokiniana isolate ND85F inoculations showed normal spore germination and germ tube growth on WT Bowman with germ tubes growing from each end of the conidium with little to no germ tube branching (Figs 4 and 5). Spore germination on the nec3- $\gamma 1$ mutant appeared normal, however, aberrant germ tube branching was consistently observed compared to the growth on WT Bowman (Figs 4 and 5). Also, after DAB staining of the nec3- $\gamma 1$ mutant, it was consistently observed that darkcolored debris would accumulate along the path of the germ tube growth across the leaf surface (Fig 4B) compared to the growth on WT Bowman (Fig 4A). As it could not be discerned if the cellular debris accumulating along the germ tube growth on the nec3- $\gamma 1$ mutant was host or pathogen-derived, electron microscopy was used to generate higher resolution images during the early infection process. These images showed that the debris was derived from the host cuticle peeling away from the leaf surface around the region of germ tube contact with the leaf surface (Fig 5).

\section{nec3 genetic map development}

A genetic map was developed using homozygous $F_{2}$ recombinant progeny from the cross between nec3- $\gamma 1$ and Quest ( $\gamma 1 \times \mathrm{Q}$ ) to map the nec3 gene. Homozygous mutant individuals were identified by inducing the nec 3 phenotype with B. sorokiniana isolate ND85F. Due to the typical recessive nature of mutant genes, a 3:1 wild type: mutant ratio was expected. Unfortunately, a lethal chlorophyll-/albino background mutation killed 54 of the $200 \mathrm{~F}_{2}$ progeny assayed. The albino mutation was not linked to nec3 and was also segregated in a recessive 3:1 single gene manner $\left(\chi^{2}=0.32\right)$. After accounting for the albino plants that died 33 of the 146 surviving plants developed the nec3 phenotype fitting the expected 3:1 ratio $\left(\chi^{2}=0.17\right)$, indicating that nec 3 was segregating as a single mutant gene in a recessive manner.

To map the Nec3 gene, the chromosome $6 \mathrm{H}$ region was saturated with molecular markers. According to the IPK cv Morex genomic sequences and POPSEQ positions [33,34], the Nec3 gene co-segregated with marker GBM1212 located at $49.07 \mathrm{cM}$ on chromosome $6 \mathrm{H}$. The proximal flanking marker GBM1423 was positioned at $49.22 \mathrm{cM}, 0.15 \mathrm{cM}$ proximal of GBM1212 and the distal flanking marker GBM1053 was positioned at $53.47 \mathrm{cM}, 4.4 \mathrm{cM}$ distal of GBM1212 (Fig 6) [34]. Thus, the $\mathrm{Nec} 3$ gene was delimited to a relatively large genetic interval of $4.55 \mathrm{cM}$. 


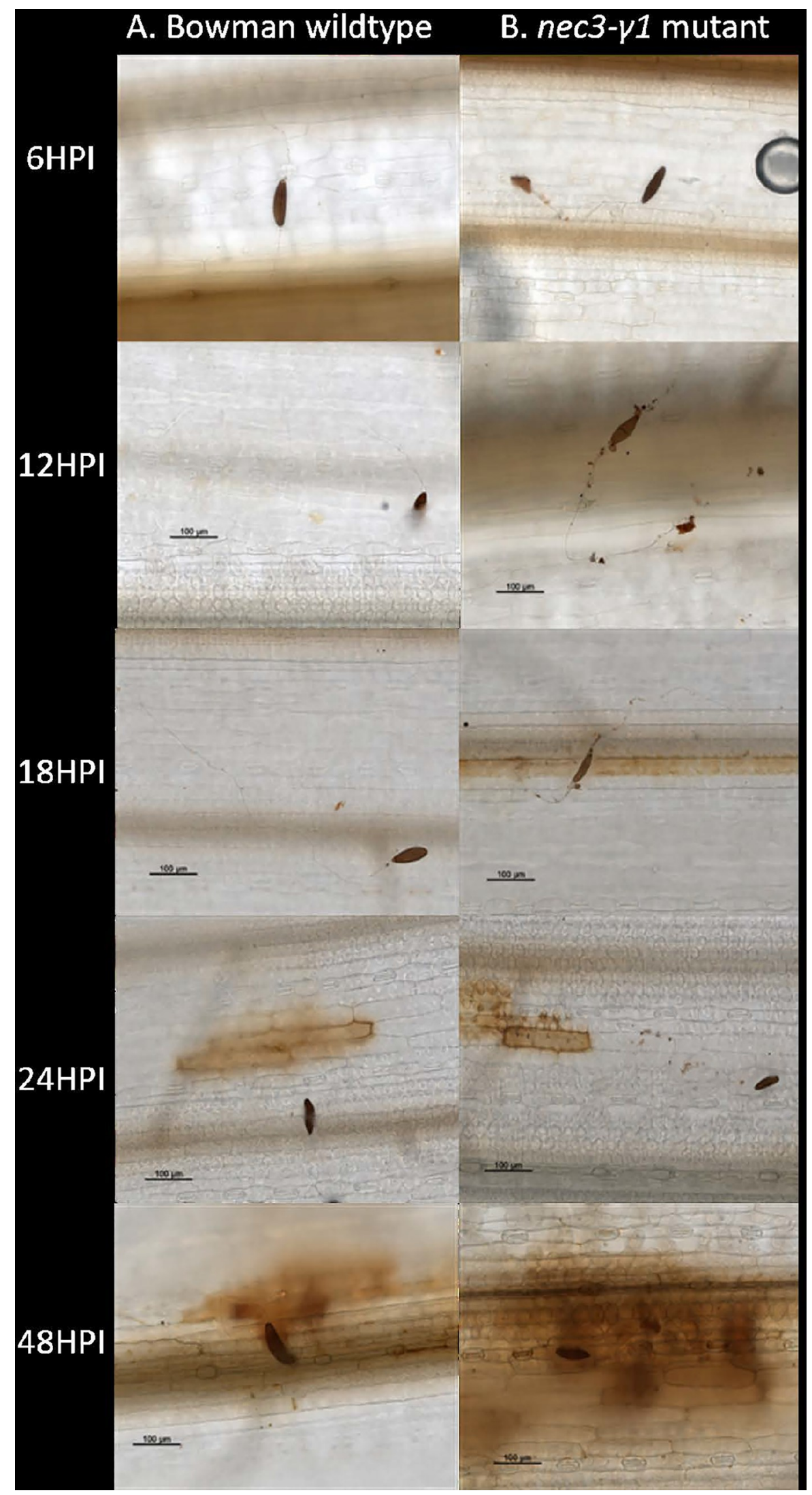


Fig 4. Microscopic visualization for comparison of the barley nec3- $\gamma 1$ mutant and Bowman wildtype for ROS production and pathogen growth on the leaf surface during infection process. On the left is the Bowman wildtype and on the right is the nec3- $\gamma 1$ mutant ROS production during infection of Bipolaris sorokiniana isolate ND85F at 6, $12,18,24,48$ hours post inoculation (HPI), where multiple branching of germ tubes, localized HR, and mutant specific interaction with the cuticle/of the barley leaves is observed as early as 12 hours post inoculation.

https://doi.org/10.1371/journal.pgen.1009473.g004

To further delimit the Nec3 region an additional 29 SNP markers were genetically anchored to the nec3 region of barley chromosome $6 \mathrm{H}$ using the $\gamma 1 \times \mathrm{Q}$ population. The positions of the 29 SNP markers on the genetic map were in perfect linear order with the newly released barley

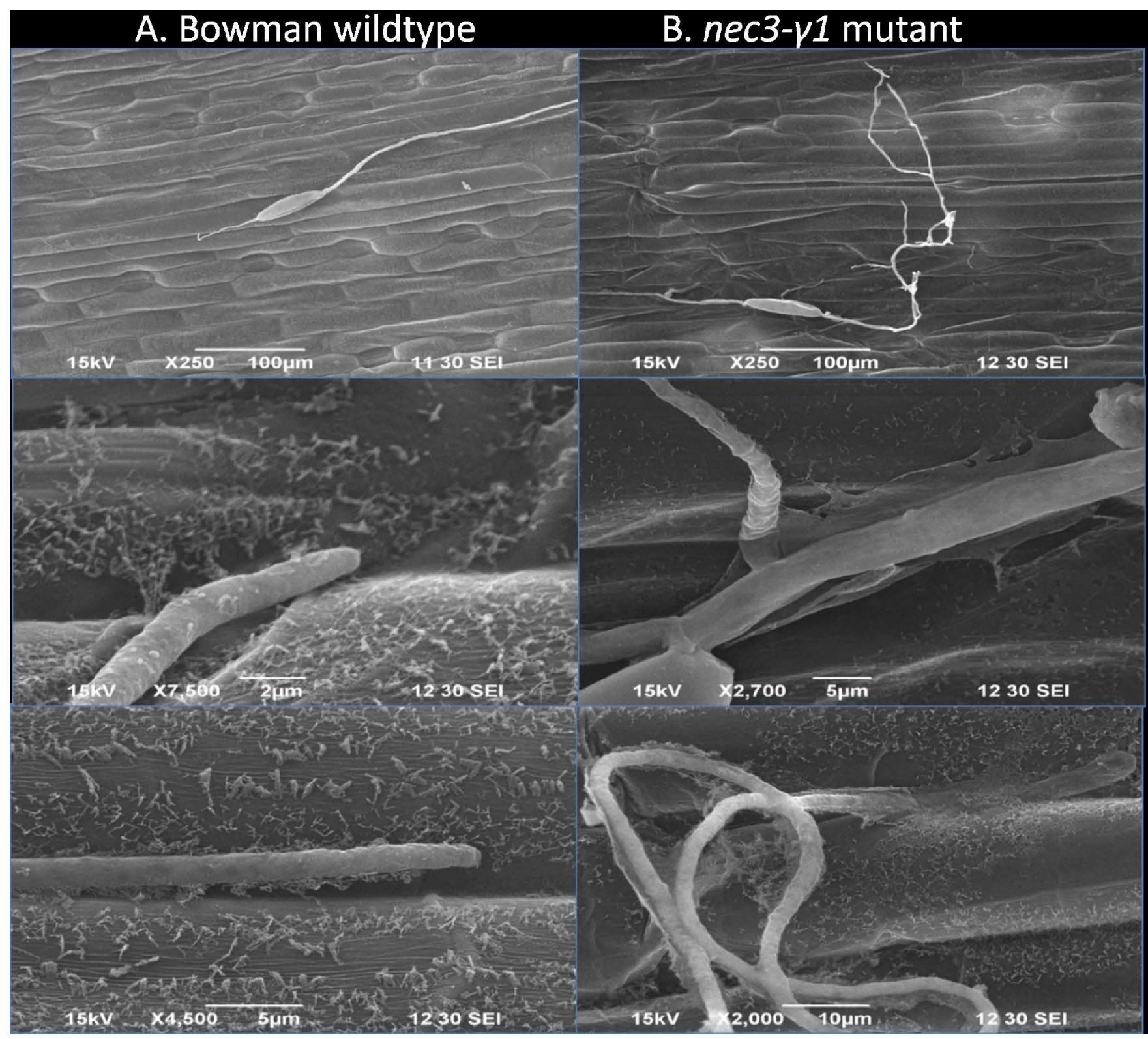

Fig 5. Electron Micrograph of the pathogen Bipolaris sorokiniana growth on the leaf surface of the barley nec3- $\gamma 1$ mutant and Bowman wildtype during the infection process. 6A. On the left is the Bowman wildtype with normal B. sorokiniana isolate ND85F growth and intact cutin layer of host at 12 hours post inoculation. 6B. On the right is abnormal growth of $B$. sorokiniana isolate ND85F with multiple branching of germ tubes and mutant specific interaction with the cuticle of the barley leaves at 12 hours post inoculation.

https://doi.org/10.1371/journal.pgen.1009473.g005 
POPSE: positions Markers Genetic Map $\quad$ Physical Map (ch. 6H)

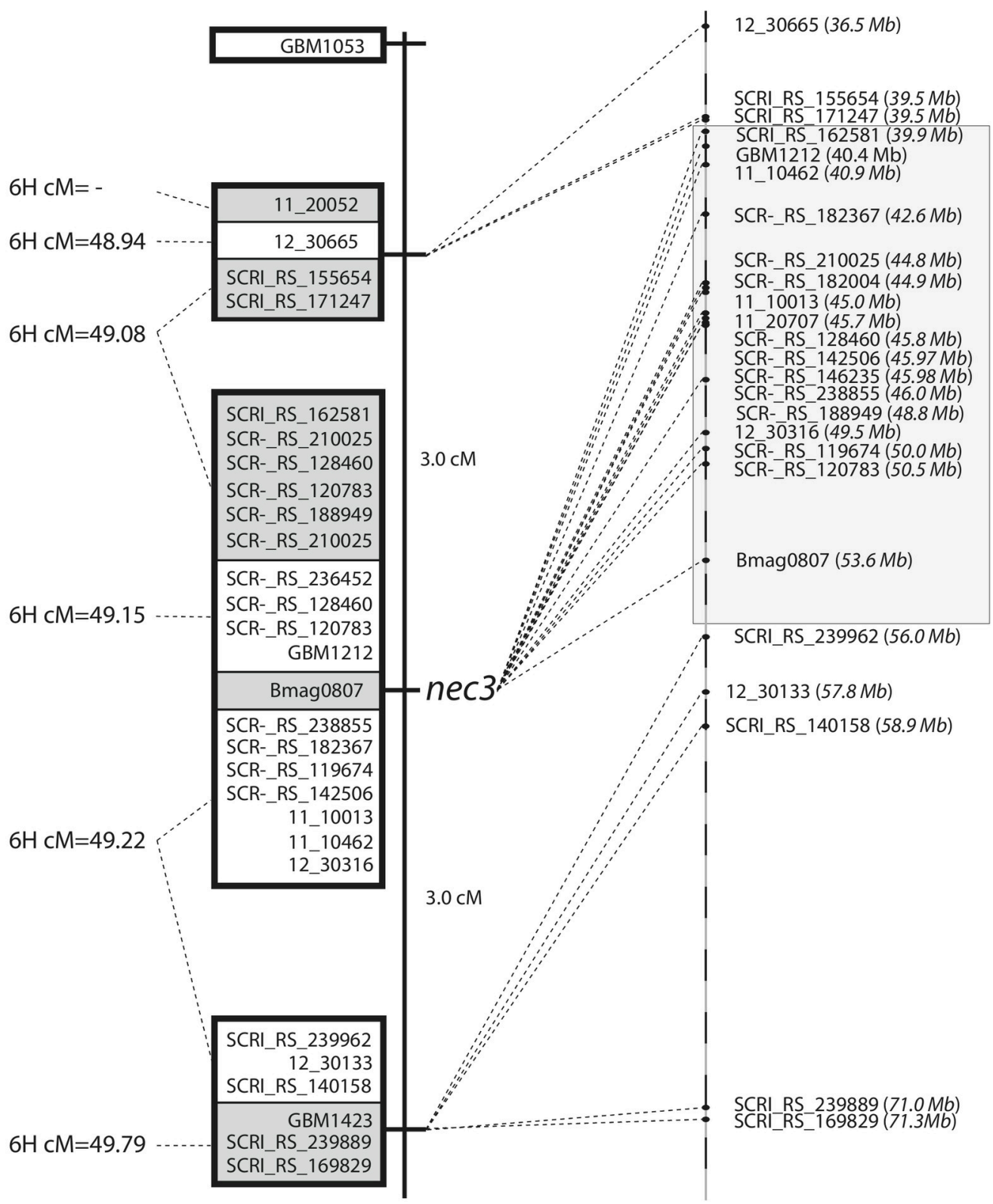

Fig 6. Genetic and physical map of the nec 3 region. On the left is the genetic map developed from 33 homozygous mutant $\mathrm{F}_{2}$ individuals (representing 66 recombinant gametes) from the cross between $n e c 3-\gamma 1$ and Quest. The genetic distances, based on recombination frequency is shown with the boxes indicating cosegregating markers based on the $\mathrm{F}_{2}$ map and white or gray shading indicating cosegregating markers based on POPSEQ consensus positions, which are given on the far left. The relative physical location of the markers is shown on the right, which were derived from the new released whole genome assembly from the IPK database.

https://doi.org/10.1371/journal.pgen.1009473.g006

genome sequence and the barley POPSEQ positions. The physical nec3 region was flanked by the SNP marker SCRI_RS_171247 distally at pseudomolecule position $39.5 \mathrm{Mb}$ and marker SCRI_RS_239962 proximally at $56.0 \mathrm{Mb}$ on chromosome $6 \mathrm{H}$, delimiting the region to $\sim 0.14$ cM based on the barley POPSEQ positions correlating to a physical region spanning $\sim 16.5$ 
$\mathrm{Mb}$ containing 149 high confidence genes according to the newly release barley genome sequence and annotation (Fig 6). The exome capture was run on the mutants nec3.l and nec3. $m$ along with the wildtype Steptoe using the capture array 120426_Barley_BEC_D04. The exome capture sequencing data were analyzed to identify potential deletions within the 149 high confidence candidate genes in the nec 3 region based on the WGA Morex sequence released in 2019 [34]. A total of 11 genes in the nec3 region were not represented in the exome capture probe set, as shown in S3 Table. The 138 annotated high confidence genes (S2 Table) present in the exome probe set and captured in the nec3 region were analyzed in WT Steptoe and the allelic mutants nec3.l and nec3.m (NCBI submission BioSample accessions SAMN22109510, SAMN22109511, SAMN22109512). No deletions were observed in the exons of the 138 genes from the three independent mutants.

\section{RNAseq and candidate gene identification}

RNAseq analysis was performed on the nec3- $\gamma 1$ mutant and WT Bowman post-inoculation with B. sorokiniana isolate ND85F to analyze the 11 genes in the delimited region missing from the exome capture analysis. The RNAseq also allowed for a thorough analysis of the global regulation of the transcriptomes in WT Bowman and the nec3- $\gamma 1$ mutant generated in the Bowman background upon B. sorokiniana isolate ND85F inoculation. To identify candidate genes, the total reads obtained and percentage alignment to the Morex reference genome was analyzed as well as comparative analysis between mutant and WT Bowman reads ( $\mathrm{S} 4$ Table) (GenBank Bio project PRJNA666939). The RNAseq analysis at 72 hpi identified a total of 10,473 differentially expressed genes (DEGs) with greater than a threefold change $(5,171$ upregulated and 5,303 downregulated) in the nec3- $\gamma 1$ mutant compared to the non-inoculated nec3- $\gamma 1$ mutant (Accession SRR12763054-SRR12763062). In resistant WT Bowman, 5,463 DEGs (2,803 upregulated and 2,661 downregulated) were identified in comparison to the noninoculated WT Bowman control. Interestingly, the comparison between Bowman and nec3- $\gamma 1$ mutant transcriptome profiles during B. sorokiniana isolate ND85F infection process revealed 3 genes upregulated in Bowman and downregulated in nec3- $\gamma 1$ mutant and nine genes were downregulated in Bowman and upregulated in nec3- $\gamma 1$ mutant (S4 Fig and S4 Table). The comparative analysis of the RNAseq data for the 11 genes missing from the exome capture probe set identified a 13 nucleotide deletion in the predicted exon 1 of the cytochrome P450 gene HORVU.MOREX.r2.6HG0460850 in the nec3- $\gamma 1$ mutant (Fig 7). Eight of the eleven genes missing from the exome capture probe were not detected at control or in the pathogeninduced samples at the tested time-point in both WT Bowman or the nec3- $\gamma 1$ mutant (S3 Table), fold changes reported as non-significant (NS). Interestingly, the candidate Nec3 gene HORVU.MOREX.r2.6HG0460850 was upregulated 1,126 fold in susceptible nec3- $\gamma 1$ mutant after pathogen inoculation and only upregulated 118 folds in WT Bowman after pathogen inoculation (S3 Table).

\section{Cytochrome P450 mutant allele analysis and functional characterization}

The candidate Nec3 Cytochrome P450 gene (HORVU.MOREX.r2.6HG0460850) was the only gene identified in the RNAseq analysis in the nec3 region that contained a mutation in nec3$\gamma 1$. Analysis of the other four independent nec3 mutants via PCR amplicon sequencing compared to their respective WT genotypes showed that all five nec 3 alleles contained a mutation that would disrupt the function of the predicted translated protein. The Nec3 gene (HORVU. MOREX.r2.6HG0460850) encodes a 1,566 bp gene (supported by RNAseq data) predicted to be translated into a 521 aa protein with an $\mathrm{N}$-terminal transmembrane domain and a C-terminal p450 domain. The p450 domain has three conserved motifs, the oxygen-binding 


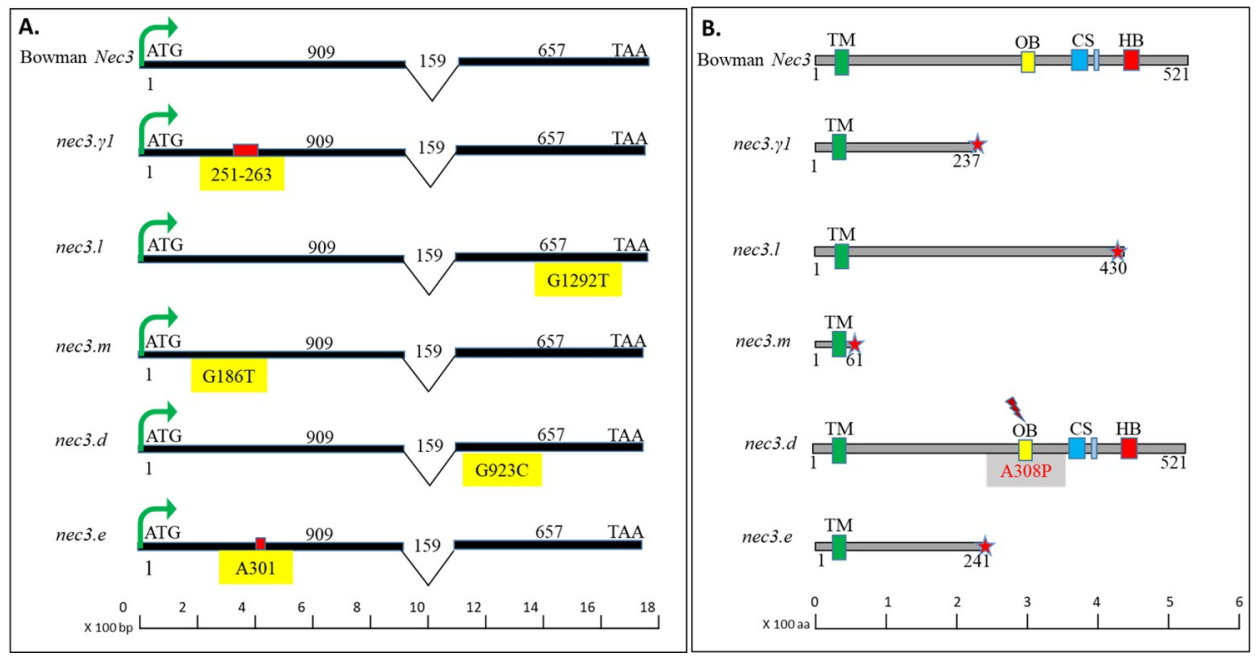

Fig 7. The allele analysis and protein polymorphism of the barley nec 3 mutants and Bowman wildtype. A. The genomic and cDNA structures for the barley Nec3 gene in bowman wildtype and nec 3 mutants are shown from top to bottom (Bowman wildtype, nec3- $\gamma 1$, nec3.1, nec3.m, nec3.d and nec3.e), where genomic and predicted mRNA structures are represented to scale with exon (black), intron (black Vs), start codon (ATG) and stop codon (TAA) and the mutations are denoted in the yellow box, where deletions are represented by red box above them. B. The barley $\mathrm{Nec} 3$ protein structure in bowman wildtype and nec3 mutants are shown from top to bottom (Bowman wildtype, nec3$\gamma 1$, nec3.1, nec3.m, nec3.d and nec3.e), where gray represent protein length, green bar represents transmembrane domain (TM), yellow bar represents oxygen binding (OB) and activation conserved residue AGxDTT, the blue bars represent the clade signatures (CS) with conserved residues ExxR and $\mathrm{P}(\mathrm{E}) \mathrm{R}(\mathrm{F})$ and red bars represent the heme binding $(\mathrm{HB})$ with conserved residues as Fxx $x$ RxCxG of the $\mathrm{p} 450$ clade. The star shows the truncated protein in the $n e c 3-\gamma 1$, nec3.1, nec3.m, and nec3.e mutant and nec3.d has a A308P substitution represented by red lightening sign in the conserved residue of Oxygen binding domain of AGxDTT to PGxDTT, in the logos of the p450 protein family in plants.

https://doi.org/10.1371/journal.pgen.1009473.g007

(AGxDTT), clade signatures (ExxR) $(\mathrm{P}(\mathrm{E}) \mathrm{R}(\mathrm{F})$ ) and heme-binding (FxxGxRxCxG) motifs (Fig 7) [35]. The nec3- $\gamma 1$ mutant has a 13-nucleotide deletion at position 251 to $263 \mathrm{bp}$ in exon1, which is predicted to result in a premature stop codon and truncated protein of $237 \mathrm{aa}$, eliminating the entire p450 domain (Fig 7). The G186T nucleotide conversion in the nec3.m was predicted to produce a premature STOP codon and a truncated protein of 61 aa eliminating the p450 domain (Fig 7). The nec3.e mutant contained the single nucleotide deletion A301 that was predicted to cause a frameshift resulting in a premature STOP codon and predicted truncated protein of 241 aa also eliminating the p450 domain (Fig 7). The G1292T nucleotide conversion in the nec3.l mutant was predicted to produce a premature STOP codon at aa position 430, eliminating the heme-binding motif present in the p450 domain (Fig 7). Intriguingly, the allelic nec3.d mutant that produces an atypical nec3 phenotype with the typical DLMM lesions that contain dark phenolics and a relatively smaller lesion size compared with the other nec3 mutants had a G923C nucleotide substitution mutation, which resulted in the predicted A308P aa conversion. This aa substitution is present in the conserved residues of the oxygenbinding (AGxDTT) motif of the $\mathrm{p} 450$ domain, yet was still predicted to produce a full-length protein. Thus, it is possible that the nec3.d mutant has compromised function but maintains partial T5H function (Fig 7). Tryptamine to serotonin conversion in the in vitro reaction mediated by yeast expressed barley $\mathrm{Nec}_{\Delta 26}$ protein could not be convincingly detected. LC-MS analysis identified an artifact peak close to the expected peak position for serotonin (S7 Fig). This Type I error was mitigated using multiple controls such as Tryptamine only and no Nec3 in the reaction, which resulted in a similar artifact peak with a minor shift in the acquisition time. 


\section{Discussion}

The cytochrome P450 gene (HORVU.MOREX.r2.6HG0460850) was identified as the Nec3 (necrotic 3) gene. Barley nec3 mutants that produce the atypical and distinct nec3 phenotype, large cream to orange necrotic lesions lacking the dark pigmentation indicative of the accumulation of serotonin phenolic compounds typical of previously reported DLMMs, were characterized in the cr Bowman, Steptoe, Proctor and Villa backgrounds. Four of the independent mutants had deletions or nucleotide substitutions in the cytochrome P450 gene that resulted in predicted nonfunctional truncated proteins. Interestingly, a fifth independent mutant shown to be allelic to nec3 produced the typical DLMM phenotype with smaller dark necrotic lesions containing serotonin or phenolics buildup (Fig 1). This nec3 mutant with a single nucleotide substitution presents a unique opportunity to investigate the role that serotonin [32] or phenolics accumulation in PCD necrotic lesions play in the sequestration of lesion expansion or pathogen colonization during HR responses. It was also discovered that nec3 is not a true DLMM as it is only expressed when the plants are challenged by diverse specialized barley pathogens.

Originally the nec3 mutants were classified as LMMs [29], referred to as disease lesion mimic mutants (DLMMs) here, that spontaneously develop necrotic lesions when they reach a certain developmental stage. However, contrary to these observations and the DLMM designation, we determined that the nec3 phenotype is only expressed when elicited by a diverse taxonomy of pathogens. The nec3 phenotype is possibly triggered through PAMP elicitor recognition, chitin in the case of fungal pathogens, during pathogen challenge, entry, and host colonization. Previous research and observations that led to the description of nec 3 as a DLMM were conducted under less controlled greenhouse and field environments, where the nec3 phenotype was consistently expressed without apparent biotic or abiotic stress induction [28]. However, in the same study, [28] it was observed that mutant seedlings grown in growth chambers for transcriptome analysis did not exhibit the nec3 phenotype. In our screen of a variety Bowman mutant population for mutants of the dominant $B$. sorokiniana isolate ND90Pr susceptibility gene [36], the nec3- $\gamma 1$ mutant was identified. The nec3- $\gamma 1$ mutant exhibited the phenotype consistent with the previously described and characterized nec3 mutants [36]. However, the phenotype appeared only after inoculation with the pathogen leading us to speculate that the nec 3 characteristic lesions were induced by pathogen challenge. To test the hypothesis that the nec 3 phenotype was only induced by pathogen infection, a sterile environmental condition experiment was conducted. Upon conducting experiments under sterile conditions with proper controls, it was determined that the nec 3 phenotype was induced in all the nec3 mutants (nec3- $\gamma 1$, nec3.d, nec3.e nec3.l, and nec3.m, by the necrotrophic ascomycete fungal pathogens $B$. sorokiniana, $P$. teres $\mathrm{f}$. teres, and $P$. teres $\mathrm{f}$. maculata, as well as the biotrophic ascomycete Blumeria graminis (Fig 2). During host penetration, these fungal pathogens are known to form appressoria-like structures and penetration pegs that puncture the cell wall and plasma membrane causing cellular damage [37-39]. The host disruption and pathogen penetrative structures are also accompanied by proteinaceous and secondary metabolite effector molecules that induce host immune responses that induce temporally regulated and spatially confined succinct PCD responses. These disruptive infection processes that induce PTI/DTI signaling also result in the upregulation of PR proteins that arrest pathogen colonization and induce systemic acquired resistance (SAR) [40].

The bacterial pathogen $X$. translucens, which causes tissue damage by employing the penetrative Type-III secretion system to deliver virulence effectors also induced the nec3 phenotype. During bacterial colonization increased extracellular polysaccharide (EPS) exudates are also released to facilitate communication between bacteria, which increases the chances of a successful infection. Bacterial pathogens also utilize enzymes and other molecules to increase 
the permeability of the cell wall. This leakiness allows nutrients to be acquired by the bacteria and facilitating its colonization. Collectively, the loss of cellular integrity induced by the bacterial pathogen may induce the nec3 phenotype or a PAMP-like bacterial elicitor also triggers the nec3 3 phenotype, however, our experiments determined that the bacterial PAMP flg22 didn't induce the nec 3 phenotype.

Interestingly, the nec 3 phenotype was not elicited by either virulent or avirulent races of the basidiomycete biotrophic pathogen P. graminis f. sp. tritici, whose strategy is "incognito" host entry through the stomata. It is hypothesized that $P$. graminis f. sp. tritici hijacks the stomatal aperture regulation of the cereal hosts to enter through the natural openings at night without being detected [41,42]. The nec3- $\gamma 1$ mutant in Bowman background contains the stem rust resistance gene $R p g 1$ [43,44], which elicits an effective race-specific immunity response yet did not elicit the nec3 phenotype. Recent research has reported that Rpg1-mediated defenses are non-HR responses [41,45], thus, suggesting that the nec 3 phenotype may still be elicited by HR-mediated resistance responses.

Necrotrophic fungal pathogens produce proteinaceous, non-proteinaceous, and secondary metabolite effectors that initiate host PCD to colonize the dead and dying tissue via necrotrophic effector-triggered susceptibility (NETS) $[12,13,46,47]$. To determine the nature of the elicitor/s of the nec3 response a pathogen culture filtrate infiltration assay was performed. $B$. sorokiniana crude culture filtrates elicited the distinct nec3 PCD phenotype on the mutants and characteristic dark pigmented lesion in the susceptible barley line Steptoe, but not in the resistant cv Bowman (S1 Fig). However, in the nec3.d mutant, culture filtrates didn't produce the pronounced dark pigmented lesions as seen with the B. sorokiniana isolate ND85F inoculations on nec3.d. Pronase treatment of the culture-filtrate did not abolish the elicitation of the distinct nec3 lesions at the infiltration site. Thus, we speculate that the pathogen effector/s in the culture filtrates that elicit the nec3 phenotype is/are not proteinaceous effector/s but rather represent a PAMP such as chitin, a secondary metabolite, a non-proteinaceous toxin, an RNA molecule or a tightly folded small protein. However, it cannot be ruled out that nec 3 is involved in suppressing PCD responses elicited by DAMPs which include cell wall components, eATP, eDNA, or other endogenous molecules disrupted during the infection process as recognition of disrupted self is seen across all multicellular life, including algae, fungi, fish, insects, mammals and plants [48]. However, our experiments showed that OGs did not elicit the nec3 phenotype.

To identify the nec3 gene a genetic map was generated with $\mathrm{F}_{2}$ recombinant progeny from the cross between nec3- $\gamma 1$ (Bowman background) and the barley variety Quest (referred to as the $\gamma 1 \times \mathrm{Q}$ population). The genetic mapping delimited the nec3 region to $\sim 0.14 \mathrm{cM}$ on barley chromosome 6H between the flanking markers SCRI_RS_155654 and SCRI_RS_239962. The SNP markers SCRI_RS_155654 resides between 39,543,736-39,543,856 base pair (bp) and SCRI_RS_239962 is situated between 56,035,754-56,035,852 bp delimiting Nec3 to a physical distance of $\sim 16.49 \mathrm{Mb}$ on barley chromosome $6 \mathrm{H}$ containing 149 high confidence annotated genes. We further analyzed these genes by carrying out whole genome exome capture sequencing on WT Bowman and WT Steptoe and three of the independent nec3 mutants, nec3- $\gamma 1$, $n e c 3-l$ and nec3-m. However, the exome capture probe library only contained probes for 138 of the 149 annotated $\mathrm{HC}$ genes present in the genetically delimited nec 3 region based on the recently refined assembly and annotation of the barley Morex reference genome (2019) [34]. Therefore, it is important to correlate the available probe set with the latest whole-genome assembly to include the potentially unannotated genes in the analysis to find the causal gene of a trait for any species. The absence of any mutated genes by exome capture analysis within the $n e c 3$ region and the identification of the 11 annotated HC genes in the nec 3 region that are missing from the exome capture probe set led to the comparative analysis approach of RNA 
sequencing of Bowman WT and the nec3- $\gamma 1$ mutant control and induced by B. sorokiniana infection ( $S 4$ Table). Utilizing the RNAseq data for comparative analysis a 13 bp deletion was identified in the HORVU.MOREX.r2.6HG0460850 HC gene model in the nec3- $\gamma 1$ mutant. Utilizing PCR amplification and Sanger sequencing we further confirmed mutations that would result in predicted nonfunctional truncated proteins in all the four independent mutants that produce the typical nec3 phenotype (nec3- $\gamma 1$, nec3.e, nec3.l, and nec3.m) and a critical amino acid substitution in the nec3.d allelic mutant that expresses the atypical dark necrotic spots (Figs 1 and 7).

The presence of irradiation-induced deletions and nucleic acid substitutions in five independent mutants confirmed that HORVU.MOREX.r2.6HG0460850 is the functional Nec3 gene. The HORVU.MOREX.r2.6HG0460850 HC gene model is predicted to encode a 521 amino acid Cytochrome P450 family protein. Cytochrome P450s are heme-thiolate proteins and represent one of the largest superfamilies of proteins with enzymatic activity. Within the superfamily, the amino acid sequence conservation is very low and only three residues belonging to the conserved sequence motif (CSM) are absolutely conserved. However, the general topography and structural folding are highly conserved across the members [49]. Only the CYP51 gene family of P450s is conserved among plant, fungi and animal phyla with the presence of CYP51 orthologs in the bacterium Mycobacterium tuberculosis, possibly due to lateral gene transfer [35].

Sequence comparison and phylogenetic analyses of the NEC3 protein places it in the CYP71 clan as a cytochrome P450 71A1-like protein (http://www.p450.kvl.dk/blast.html), suggesting involvement in plant lineage-specific metabolism [50] (S5 Fig). Upon annotating the putative protein-coding sequences of the five allelic nec 3 mutants, four were predicted to encode premature stop codons due to the induced mutations and one had a single nucleotide substitution that resulted in an A308P amino acid conversion in the predicted oxygen binding and activation domain in the conserved P450 residues (Fig 7). The data showed that upon pathogen infection, this mutant nec3.d allele was induced and predicted to be translated into a full-length protein with a nonfunctional oxygen-binding domain due to the single amino acid substitution (Fig 7). Interestingly, the nec3.d mutant although allelic to the truncated nonfunctional nec 3 alleles expresses comparatively smaller dark pigmented lesions presumed to be due to higher serotonin/phenolics accumulation. We hypothesize that the smaller lesion size of nec3. $d$ compared to the typical cream-colored nec3 phenotypes expressed by nec3- $\gamma 1$, nec3.e, $n e c 3 . l$, and nec3.m mutants were due to a partially functional Nec3 protein yet elicited the DLMM phenotype due to its compromised oxygen-binding domain. Another possibility to describe this anomaly is pathogen sequestration due to the serotonin/phenolics accumulation in the lesions. We assessed the role of exogenous root feeding of serotonin and tryptamine in these mutants and found that artificial availability of serotonin to supplement the deficiency did reduce the size of the nec3 lesion and over-accumulation of tryptamine increased the lesion size in wildtype and mutants. Suggesting, that the sequential conversion of tryptamine into serotonin is mediated by $\mathrm{Nec} 3$, which is predicted to encode a tryptamine 5-hydroxylase $(\mathrm{T} 5 \mathrm{H})$ and exogenous application of upstream or downstream substrates in the pathway can modulate the final phenotypic outcome.

These observations and apparent phenotypic differences suggest that the oxygen binding domain plays a critical role in the NEC3 protein function in regulating PCD as well as the pathway leading to serotonin accumulation [32]. The nec3.d allele presents a unique tool for further functional characterization of the role of serotonin/phenolic deposition in necrotic lesions and their role in pathogen sequestration or the regulation of lesion expansion. As the question of how or why serotonin/phenolics build up in PCD induced necrotic lesions is an important question that still needs to be answered. 
Interestingly, the Sekiguchi lesion $(s l)$ mutant in rice produces orange tan necrotic lesions, similar to the barley nec 3 phenotype. The $s$ gene was identified via map-based cloning and shown to encode CYP71P1 in the cytochrome P450 monooxygenase family that shares $90.1 \%$ amino acid similarity and $86.7 \%$ identity with the barley Nec3 protein (S6 Fig) [32]. The $s l$ gene was shown to encode a Tryptamine 5-Hydroxylase (T5H) enzyme that converts tryptamine to serotonin in plants in the shikimic pathway [32]. The rice $s l$ gene mutants were susceptible to the rice blast fungus (Magnaporthe grisea) and rice brown spot fungus (Bipolaris oryzae) and the $s l$ necrotic lesions were also induced by the $\mathrm{N}$-acetylchitooligosaccharide (chitin) elicitor [31]. The $s l$ mutant susceptibility to rice blast was eliminated by exogenous application of serotonin in rice leaves [31]. The exogenously applied serotonin was deposited into the cell wall of the $s l$ lesion tissue and these lesions with additional serotonin phenolics had restored dark pigmentation and restored resistance to the necrotrophic pathogen B. oryzae [32]. Thus, the nec3.d mutant containing the partially functional full-length protein may be able to convert Tryptamine to Serotonin but due to the critical A308P substitution has a leaky control on PCD and is not able to keep it in check upon pathogen recognition. We tested the T5H functional capability of Nec3 protein, however, we couldn't convincingly detect the Tryptamine to serotonin conversion in the in vitro reaction mediated by yeast expressed barley $\mathrm{Nec}_{\Delta 26}$ protein. Increased level of Serotonin due to root-feeding was able to reverse the nec3 phenotype in vivo, nonetheless, failure to determine the in vitro T5H activity of $\mathrm{Nec} 3$ could possibly be attributed to its specificity to the species-specific reductase or requirement of additional in vivo activity components that are yet to be determined.

Plants have evolved oxidative polymerization of serotonin in the modification of cell walls as part of the physical barrier and phenolics deposition at the infection site during pathogen infection to inhibit pathogen growth and sequester them in the foci of dead cells. This mechanism may also act as a signaling mechanism to sequester lesion expansion to preserve the leaf s photosynthetic capability after reacting to pathogen challenge. The barley nec3 mutants fail to regulate the PCD response, providing expanding necrotic lesions with no defined border. This was further exemplified by the nec3. $d$ mutant that still accumulates phenolics and has a defined lesion border that sequesters the expansion of the lesion in the presence of the pathogen. This phenomenon is also observed in resistant WT Bowman. The RNAseq analysis showed that the barley NEC3 gene is highly upregulated in WT Bowman and the nec3- $\gamma 1$ mutant, 72 hours post B. sorokiniana inoculation, thus the upregulation of the $s l$ ortholog suggests an increased need to convert Tryptamine to Serotonin in barley as well because of its importance in regulating PCD-mediated immunity.

Necrotrophic fungal pathogens produce proteinaceous, non-proteinaceous, and secondary metabolite effectors that initiate host PCD to colonize the dead and dying tissue via necrotrophic effector-triggered susceptibility. To determine the nature of the elicitor/s of the nec3 response a pathogen culture filtrate infiltration assay was performed. B. sorokiniana crude culture filtrates elicited the distinct nec3 PCD phenotype on the mutants and characteristic dark pigmented lesion in the susceptible barley line Steptoe, but not in the resistant cv Bowman. However, in the nec3.d mutant, culture filtrates did not produce pronounced dark pigmented lesions as seen with the B. sorokiniana ND85F isolate inoculation on nec3.d. This suggests that this single amino acid substitution allows for the induction of enhanced PCD elicitation by the pathogen in the WT Bowman background yet possibly still retains partial function allowing for serotonin metabolism and build up in the lesions that still functions to sequester the pathogen and necrotic lesion expansion. The culture filtrate infiltration of the nec3. $d$ mutant was indistinguishable from the other nec3 mutants with no dark pigmentation in the absence of the pathogen. This suggested that post-elicitation, the nec3.d mutant behaves similarly to the other nonfunctional mutants but in the presence of the pathogen, it is still able to mount some level of serotonin biosynthesis and suppression of lesion expansion and pathogen growth. 
The pronase treatment of the culture-filtrate did not abolish the elicitation of the distinct $n e c 3$ lesions at the infiltration site. Thus, we can speculate that the pathogen effector/s in the $B$. sorokiniana culture filtrates that elicit the nec3 phenotype is not a proteinaceous effector but similar to the $s l$ mutant in rice may be elicited by a PAMP, possibly chitin as it elicited the $s l$ phenotype and possibly elicits nec 3 in barley as well. This would suggest that the nec 3 necrosis may be elicited by chitin through extracellular LysM domains, present on barley orthologs of the rice LysM RLK, OsCERK1, and the LysM RLP CEBiP [51]. However, due to the observation that the nec3 phenotype is also elicited by the bacterial pathogen $X$. translucens there is a possibility multiple effectors inducing PCD responses suppressed by Nec3.

In Arabidopsis, the CYP84A1 EMS mutant was shown to have altered lignin composition [52]. Thus, alterations of the cell wall composition could affect the pathogen's spatiotemporal interactions with the host at the leaf surface, which we tested microscopically in the nec3- $\gamma 1$ mutant. Upon microscopic observations of B. sorokiniana growth pattern on the nec 3 mutant compared to WT Bowman it was observed that the pathogen's infection hyphae interaction with the host cuticle was abnormal showing that the cuticle was unstable and peeled away from the nec3- $\gamma 1$ leaf surface, where there was contact (Fig 5B). This aberrant interaction apparently disrupted the signaling in the pathogen's infection hyphae. When growing across the nec 3 mutant leaf surface the B. sorokiniana hyphae branched profusely and produced surface debris apparently due to unstable cuticle along the germ tubes (Fig 5). The profuse branching of pathogen and plant cell surface destabilization could result in many host-pathogen contact points with the nec 3 mutants allowing the plants to recognize more PAMP molecules, possibly chitin fragments. This aberrant interaction possibly leads to the rapid ROS production in nec 3 cyp $71 \mathrm{~A} 1$ mutants and the runaway cell death due to the lack of serotonin accumulation, which may play a role in the sequestration of PCD mediated lesion expansion of the necrotic lesions similar to the $s l$ mutant in rice. The DAB assays supported this conclusion as the nec3- $\gamma 1$ mutant produced ROS when infected by the necrotrophic pathogen B. sorokiniana as early as $12 \mathrm{hpi}$ as compared to a delayed ROS in the susceptible Steptoe and resistant Bowman, which was detected at 18 and 24 hpi, respectively (Fig 4).

Here we report on the identification of the barley Nec3 gene as a P450 CYP71A1 cytochrome oxidase that plays a role in suppressing $\mathrm{PCD}$ responses that are initiated by diverse adapted barley pathogens. We hypothesize that Nec3 is a negative regulator of the PCD and is an ortholog of the $s l$ gene identified and characterized in rice, which plays a role in serotonin biosynthesis and buildup in necrotic lesions. The barley Nec3 gene provides a valuable resource to study the control of PCD and HR responses and our collection of mutant alleles especially the nec3.d mutant will be an excellent tool for determining the role of serotonin and possibly phenolic compound deposition in necrotic lesions for the sequestration of pathogen colonization or lesion expansion.

\section{Materials and methods}

\section{Elicitation of nec3 phenotype}

An isolation box experiment was performed on the wildtype (WT) $\mathrm{cv}$ Bowman and nec3- $\gamma 1$ (Bowman background) seeds over a month to observe the nec3 phenotype independent of pathogen challenge with details in S1 Appendix.

\section{Pathogens that induce nec3 phenotypes}

To determine if diverse pathogens could induce the nec 3 phenotype, inoculations of the mutant line nec3- $\gamma 1$ and WT lines were performed using diverse fungal pathogens, including B. sorokiniana, Pyrenophora teres $\mathrm{f}$. teres, Pyrenophora teres $\mathrm{f}$. maculata, Pyrenophora tritici- 
repentis, Parastagonospora nodorum, Cercospora beticola, and virulent and avirulent races of Puccinia graminis $\mathrm{f}$. sp. tritici. The barley bacterial pathogen Xanthomonas translucens pv undulosa was also used to inoculate the plants. The materials and methods followed are described in S1 Appendix.

\section{Infiltrations with DAMPs}

Culture filtrate infiltrations were performed for B. sorokiniana isolate ND85F $1 \mathrm{~mL}$ of the suspension (10-20k spores) was taken from the plates and added to $75-100 \mathrm{~mL}$ of Fries media (56). The flasks containing Fries media and B. sorokiniana spores were incubated at $26^{\circ} \mathrm{C}$ in the dark for three days with shaking at 100rpm then placed in the dark at room temperature with continued shaking for an additional four days. Following 7 days of growth, the exudates were filtered with Miracloth and concentrated using a 15mL Microsep Advance Centrifugal Device with a $3 \mathrm{kD}$ size exclusion to concentrate the exudates $\sim 8 \mathrm{x}$. A syringe without a needle was used to infiltrate four secondary leaves of WT Bowman, WT Steptoe, nec3- $\gamma 1$, WT Quest, nec3.l and nec3.m, nec3.d and nec3.e. The four treatments consisted of; 1) concentrated exudates + Fries Media, 2) concentrated exudates + MOPs buffer, 3 ) concentrated exudates + MOPs + Pronase (Sigma), and 4) Fries media + MOPS + Pronase. All treatments, concentrated exudates + Fries media, and concentrated exudates + MOPS were at 1:1 ratio with specifications performed according to Liu 2004 (57). Pronase treatments were performed at 1mg/ $\mathrm{mL}$ and leaves were scored 4 and 7 days after infiltrations.

Infiltrations were also performed with trigalacturonic acid, Flg22 and Chitin. Wildtype Steptoe and Bowman, nec3.l and nec3- $\gamma 1$ were infiltrated with the DAMP trigalacturonic acid at $10 \mathrm{mg} / \mathrm{mL}, 1 \mathrm{mg} / \mathrm{mL}$ and $0.1 \mathrm{mg} / \mathrm{mL}$. with Flg22, a PAMP at $1 \mathrm{mg} / \mathrm{mL}$ and Chitin at $2 \mu \mathrm{g} / \mathrm{ml}$. All infiltrations with the controls were performed at the two-leaf stage. Following infiltration, plants were kept in a growth chamber with a 14-hour photoperiod at $22^{\circ} \mathrm{C}$ and 10 hours of dark at $18^{\circ} \mathrm{C}$. Plants were observed every day up to seven days after infiltration.

\section{DAB staining}

To observe ROS at the site of infection, five $3 \mathrm{~cm}$ leaf samples were collected from secondary leaves at 6,12,18, 24 and $48 \mathrm{hpi}$ from WT Bowman and nec3- $\gamma 1$ mutant seedlings inoculated with B. sorokiniana isolate ND85F. After detachment, the leaves were immediately transferred to $10 \mathrm{ml}$ of freshly prepared $1 \mathrm{mg} / \mathrm{ml} \mathrm{DAB}$ (Sigma Aldrich, MO) solution ( $\mathrm{pH} 3.6$ ) in $15 \mathrm{ml}$ tubes following the protocol described by [53].

\section{Electron microscopy}

Electron microscopy was performed on leaves collected from WT Bowman and nec3- $\gamma 1$ mutant seedlings at $12 \mathrm{hpi}$ with B. sorokiniana isolate ND85F. The leaves were collected and cut into squares with a razor blade, fixed in $2.5 \%$ glutaraldehyde in sodium phosphate buffer (Tousimis, Rockville, Maryland USA) and stored at $4^{\circ} \mathrm{C}$ overnight. The sectioned leaf samples were rinsed with distilled water followed by rinsing with sodium phosphate buffer $1 \mathrm{M}$ solution at $7.4 \mathrm{pH}$ and then dehydrated using eight washes of a graded alcohol series from $30 \%$ to $100 \%$ ethanol with incremental concentrations increased by $10 \%$ for each wash. The leaf samples were critical-point dried using an Autosamdri-810 critical point drier (Tousimis, Rockville, Maryland USA) with liquid carbon dioxide as the transitional fluid. The dried leaf samples were attached to aluminum mounts with silver paint (SPI Supplies, West Chester, Pennsylvania USA) and sputter-coated with gold (Cressington sputter coater Redding, California USA). Images were obtained using a JEOL JSM-6490LV scanning electron microscope operating at an accelerating voltage of $15 \mathrm{kV}$. 


\begin{abstract}
Allelism crosses
The nec3- $\gamma 1$ mutant identified in this study was crossed with nec3.1, nec3.m, nec3.d and nec3.e. The resulting $\mathrm{F}_{1}$ seed was planted in the field with WT parental lines Steptoe and Bowman and phenotyped from seedling to adult plant stages. The $\mathrm{F}_{2}$ progeny were planted in the greenhouse and inoculated with the B. sorokiniana isolate ND85F and the nec 3 phenotype/disease was rated on the secondary leaves of the seedlings. The phenotyping was performed in the field and greenhouse to take advantage of the entire year. This was made possible due to the consistency of elicitation of the nec3 phenotype when grown adjacent to susceptible spreader rows inoculated with the $B$. sorokiniana isolate ND85F in the field and when inoculated in the greenhouse with B. sorokiniana isolate ND85F.
\end{abstract}

\title{
Nec3 map development
}

The original nec3- $\gamma 1 \mathrm{M}_{2}$ plant generated in the $\mathrm{cv}$ Bowman background was utilized as the female parent in a cross with the six-rowed cv Quest that was originally developed for malting and released by the University of Minnesota (59). Two hundred nec3- $\gamma 1$ x Quest $\mathrm{F}_{2}$ individuals were screened in the greenhouse for the nec 3 phenotype after inoculation with B. sorokiniana isolate ND85F as previously described and a chi-square test was used to determine the goodness of fit. Allelism tests had determined that nec3- $\gamma 1$ was a nec3 mutant. Thus, to map the gene more precisely simple sequence repeat (SSR) and single nucleotide polymorphism (SNP) markers spanning the previously delimited nec3 region near the centromere of barley chromosome $6 \mathrm{HS}$ were used to genotype the $\mathrm{F}_{2}$ individuals showing the homozygous nec 3 mutant phenotype. Unfortunately, a lethal chlorophyll/albino background mutation killed 54 of the $200 \mathrm{~F}_{2}$ progeny assayed. This background chlorophyll/albino mutation segregated in a recessive 3:1 single gene manner $\left(\chi^{2}=0.32\right)$. This mutation was not linked to nec 3 and we accounted for the plants that died and the number of remaining plants that developed the nec3 phenotype to calculate the genetic ratio. Genomic DNA was extracted from nec3- $\gamma 1$, Quest and 33 homozygous nec3- $\gamma 1 \mathrm{~F}_{2}$ progeny representing 66 recombinant gametes. Four microsatellite markers designated Bmag0807, GBM1053, GBM1212, and GBM1423 were PCR amplified using oligonucleotide primers designed from the publicly available probe sequences mined from GrainGenes [54].

\section{PCR-GBS library preparation, Ion Torrent sequencing and SNP calling}

A PCR genotyping-by-sequencing (PCR-GBS) panel was developed using SNP source file sequences mined from the T3 database [55] as previously described [56]. The POPSEQ positions were utilized from the IPK Barley BLAST Server [33] to identify 43 SNP markers that mapped to the nec3 locus between the SSR markers GBM1053 and GBM1423. The parental lines nec3- $\gamma 1$ (cv Bowman) and cv Quest plus the $33 \mathrm{~F}_{2}$ homozygous nec3 mutant recombinants were assayed. The PCR-GBS library preparation, Ion Torrent sequencing and SNP calling were performed as described before [56,57]. However, due to the low number of lines and markers, the library was sequenced on an Ion Torrent PGM 314 chip. The genetic map in the delimited region was generated manually and the POPSEQ positions of each marker were mined from the IPK genome browser.

\section{Physical map development and candidate gene identification}

The 43 SNP markers were anchored to the IPK barley BLAST server (https://webblast.ipkgatersleben.de/barley_ibsc/viroblast.php) based sequence and a physical position search was conducted against the 2019 Whole genome assembly of barley cv Morex sequences to create a 
minimum tiling path (MTP) physical map. The flanking markers GBM1053 and GBM1423 and the 43 SNP marker data on the nec3- $\gamma 1$ (cv Bowman) and cv Quest and $33 \mathrm{~F}_{2}$ recombinants (66 recombinant gametes) were used to develop the genetic map and were anchored to the WGS of barley to determine the physical map for the delimited Nec3 region. The delimited $\mathrm{Nec} 3$ region with flanking markers was used to list all the high confidence annotated genes in the region that were considered as candidate genes based on the 2019 Whole genome assembly of barley cv Morex [34].

\section{Exome capture and analysis}

DNA was extracted from excised embryos of five germinated seeds of WT Bowman, WT Steptoe, nec3- $\gamma 1$ (Bowman background), nec3.l (Steptoe background), and nec3.m (Steptoe background) mutants. DNA extractions were performed on mechanically lysed samples using the PowerPlant Pro DNA isolation kit (Qiagen, CA), following the protocol described by Solanki et al. [57].

\section{RNAseq}

The WT Bowman and nec3- $\gamma 1$ seedlings were grown for $\sim 14$ days until the secondary leaves were fully expanded in a growth chamber set at 14 hours light at $22^{\circ} \mathrm{C}$ and 10 hours dark at $19^{\circ} \mathrm{C}$. The seedlings were inoculated with B. sorokiniana isolate ND85F following the procedure described earlier and the control seedlings were inoculated with water mixed with two drops of Tween20. Secondary leaf tissue was collected from three biological replicates (one individual seedling was considered as a biological replicate) from non-inoculated and inoculated seedlings at 72 hours post-inoculation (hpi) and total RNA was extracted using the RNeasy Mini kit (Qiagen, CA). The RNAseq library was constructed using TruSeq RNA library prep kit v2 (Illumina, CA) and sequenced on the Illumina NextSeq 500 (S1 Appendix). The final list was then produced by using the candidate genes in the mapped Nec3 physical region with differential expression between the WT Bowman and nec3- $\gamma 1$ mutant DEGs during pathogen interaction. The reads pile-up from the differentially expressed candidate genes were aligned from WT Bowman and nec3- $\gamma 1$ mutant (Bowman background) and deletions were observed in the gene-specific reads pile-up on the CLC Genome Workbench 8.0.3.

\section{Candidate nec3 gene allele analysis and protein function characterization}

The candidate nec3 gene HvCYP71-A1 was amplified from the nec3- $\gamma 1$ (Bowman background), WT Bowman, nec3.1 (Steptoe background), nec3.m (Steptoe background), WT Steptoe, nec3.d (Proctor background), WT Proctor, nec3.e (Villa background) and WT Villa using the primer pairs Nec3_p450_F1 and Nec3_p450_R1; Nec3_p450_F3 and Nec3_p450_R2; Nec3_p450_F4 and Nec3_p450_R4 that were designed to produce overlapping amplicons with the respective fragment sizes of 1075, 563 and $404 \mathrm{bp}$ (S4 Table). The purified PCR amplicons were sequenced using Sanger sequencing (Genscript, NJ). The overlapping PCR amplicon sequences were aligned and the specific mutations for each nec3 mutant as compared to their respective wild type were determined.

The Nec3 proteins' possible T5H activity to convert Tryptamine to Serotonin was tested in vitro as described in Fujiwara et al. (2010). The partial Nec3 protein $\left(\mathrm{Nec}_{\Delta 26}\right)$ was expressed in the X33 strain of Pichia pastoris with a c-terminal 6x His tag. The initial 26 amino acid encode a predicted transmembrane domain, thus was removed for the secreted protein expression. Secreted protein was purified by His-NTA column and analyzed by SDS-PAGE and western blot assays (S7 Fig). The $150 \mu \mathrm{l}$ in vitro reaction consisted of $20 \mathrm{mM}$ potassium phosphate (pH 7.25), $50 \mathrm{pmol} / \mathrm{ml}$ recombinant Nec3 protein, NADPH reductase from rabbit liver, and 
$100 \mu \mathrm{M}$ tryptamine. Reactions were initiated by adding $1 \mathrm{~mm} \mathrm{NADPH}$ and incubated at $30^{\circ} \mathrm{C}$ for $30 \mathrm{~min}$. Three controls, i.e., tryptamine $(1 \mathrm{ng} / \mu \mathrm{l})$ only, full reactions without $\mathrm{Nec} 3$, and without NADPH was carried out in parallel. After incubation samples were spiked with deuterated Serotonin as an internal control, diluted 1:5 with ice-cold methanol and centrifuged at maximum speed for 15 minutes to get the supernatant, which was concentrated overnight in the speed vacuum. Final samples were subjected to LC-MS analysis on Agilent 6495 triple quadrupole system for Tryptophan to Serotonin conversion analysis.

\section{Exogenous supplementation of Serotonin and Tryptamine}

In three sets of treatments six replicates each of nec 3 mutants and their respective wildtypes were fed serotonin $150 \mathrm{Mm}$, Tryptamine $5 \mathrm{mM}$ and water at $40 \mathrm{ml} /$ plant through roots starting at 5 days old seedlings for every alternate day for total of 10 feedings. The plants were inoculated with B. sorokiniana isolate ND85F spores at $2000 / \mathrm{ml}$ on the 14 days old seedling by following previously described protocol and phenotyped on day $21^{\text {st }}$ after 7 days of disease infection.

\section{Supporting information}

\section{S1 Appendix. Materials and methods. (DOCX)}

S1 Table. List of markers used to develop the barley nec3 genetic and physical map on the chromosome $6 \mathbf{H}$. The markers name, their sequence and physical position based on the 2019 Whole Genome Assembly of barley cultivar Morex.

(XLSX)

S2 Table. The list of high confidence candidate genes in the delimited nec3 region of the barley genome. The gene name, physical position, their presence on the Exome Capture Probe and annotation is based on the 2019 Whole Genome Assembly of barley cultivar Morex. (XLSX)

S3 Table. The list of high confidence candidate genes in the delimited nec3 region of the barley genome that were not captured in the exome capture experiment were further analyzed for their expression during the spot blotch infection at $\mathbf{7 2}$ hours post inoculation. The gene name, and annotation is based on the 2019 Whole Genome Assembly of barley cultivar Morex and the relative normalized expression is reported in the Bowman wild type and $n e c 3-\gamma 1$ transcriptome profile of spot blotch infection, where no-significant change from control is denoted by the NS.

(XLSX)

S4 Table. The List of primers used in the Nec3 study. (XLSX)

S1 Fig. Typical reactions of Bipolaris sorokiniana isolate ND85F culture filtrates on nec3 mutants and wildtype (wt) parental lines. Infiltrations of secondary leaves of barley lines Bowman wt, nec3- $\gamma 1$, nec3.d, nec3.e., Steptoe wt, nec3.l, and nec3.m (left to right) with Bipolaris sorokiniana isolate ND85F culture filtrates $(\mathrm{CF})$. The treatments from top to bottom (indicated to the left) were culture filtrates (CF) with Fries media (FM); CF with MOPS buffer (M); CF with $\mathrm{M}$ and pronase (P); and the control containing FM, $\mathrm{M}$ and $\mathrm{P}$. Infiltrations were performed at the two-leaf stage and documented 4 and 7 days after infiltration. Pictures shown were taken at 7 days post infiltration.

(TIF) 
S2 Fig. The nec3 phenotype was not induced by chitin infiltrations on the nec3 mutants and their respective wildtype barley plants. (A.) The panel shows the reaction to the chitin $2 \mu \mathrm{g} / \mathrm{ml}$ infiltrations on the nec3 mutants from the left nec3.d, nec3. $\gamma 1$, nec3.e, nec3.l and nec3. $m$, followed by the Bowman, Steptoe, Proctor, Villa wildtypes. (B.) The panel shows the reaction to the control buffer infiltrations on the nec3 mutants from the left nec3.d, nec3. $\gamma 1$, nec3.e, $n e c 3 . l$ and nec3.m, followed by the Bowman, Steptoe, Proctor, Villa wildtypes.

(TIF)

S3 Fig. The nec3 phenotype induced by Bipolaris sorokiniana inoculation on the secondary leaf of the nec3 mutants (A.) and their respective wildtype barley plants (B.), where plants were supplied with $40 \mathrm{ml} /$ pot of water; serotonin $150 \mu \mathrm{g} / \mathrm{ml}$ and Tryptamine $5 \mathrm{mM}$ on every alternate days starting from 5 days old seedling for a total of 10 root feedings.

S4 Fig. The transcriptome profile of the Bowman wildtype and nec3- $\gamma 1$ mutant after 72 hours post inoculation of Bipolaris sorokiniana isolate ND85F. The venn-diagram represents the number of unique genes in a given class, where the blue and green oval represents Bowman downregulated and upregulated genes, respectively and the red and yellow oval represents nec3- $\gamma 1$ mutant upregulated and downregulated genes, respectively (Top image). The bar graph shows the number of total genes present in each class Bowman and nec3- $\gamma 1$ mutant up and down-regulated genes (Bottom image). (TIF)

S5 Fig. The NCBI blast phylogenetic tree of the barley Nec3 protein, where the branch represents the relationship between the close orthologs of the proteins in monocots. (TIF)

S6 Fig. The similarity between the barley Nec3 and the rice $s l$ protein, where the dots represent same and the letters represents the different amino acid differences in the two proteins.

S7 Fig. LC-MS analysis of the Purified Nec3 326 protein's possible Tryptamine 5-Hydroxylase activity to convert Tryptamine to Serotonin was tested in vitro as described in Fujiwara et al. (2010), using three controls, i.e., tryptamine $(1 \mathrm{ng} / \mathrm{\mu l})$ only, full reactions without Nec3 $\triangle 26$, and without NADPH was carried out in parallel on Agilent 6495 triple quadrupole system.

\section{Acknowledgments}

The nec3.d and nec3.e mutants were kindly provided by Dr. Jerry Franckowiak. The nec3.1 and nec3.m mutant lines were kindly provided by Dr. Andris Kleinhofs, Washington State University. We are thankful for the Center for Mass Spectrometry and Proteomics at the University of Minnesota for the LC-MS facility.

\section{Author Contributions}

Conceptualization: Gazala Ameen, Shyam Solanki, Timothy L. Friesen, Robert S. Brueggeman.

Data curation: Jonathan Richards. 
Formal analysis: Gazala Ameen, Shyam Solanki, Jonathan Richards, Robert S. Brueggeman.

Investigation: Gazala Ameen, Shyam Solanki, Lauren Sager-Bittara, Prabin Tamang.

Methodology: Gazala Ameen, Shyam Solanki, Lauren Sager-Bittara.

Project administration: Robert S. Brueggeman.

Supervision: Timothy L. Friesen, Robert S. Brueggeman.

Validation: Shyam Solanki.

Writing - original draft: Gazala Ameen.

Writing - review \& editing: Gazala Ameen, Shyam Solanki, Jonathan Richards, Prabin Tamang, Timothy L. Friesen, Robert S. Brueggeman.

\section{References}

1. Van Hautegem T, Waters AJ, Goodrich J, Nowack MK. Only in dying, life: programmed cell death during plant development. Trends Plant Sci. 2015; 20: 102-113. https://doi.org/10.1016/j.tplants.2014.10.003 PMID: 25457111

2. Lo Presti L, Lanver D, Schweizer G, Tanaka S, Liang L, Tollot M, et al. Fungal effectors and plant susceptibility. Annu Rev Plant Biol. 2015; 66: 513-545. https://doi.org/10.1146/annurev-arplant-043014114623 PMID: 25923844

3. Macho AP, Zipfel C. Plant PRRs and the activation of innate immune signaling. Mol Cell. 2014; 54 263-272. https://doi.org/10.1016/j.molcel.2014.03.028 PMID: 24766890

4. Jia Y, McAdams SA, Bryan GT, Hershey HP, Valent B. Direct interaction of resistance gene and avirulence gene products confers rice blast resistance. EMBO J. 2000; 19: 4004-4014. https://doi.org/10 1093/emboj/19.15.4004 PMID: 10921881

5. Deslandes L, Olivier J, Peeters N, Feng DX, Khounlotham M, Boucher C, et al. Physical interaction between RRS1-R, a protein conferring resistance to bacterial wilt, and PopP2, a type III effector targeted to the plant nucleus. Proc Natl Acad Sci USA. 2003; 100: 8024-8029. https://doi.org/10.1073/ pnas.1230660100 PMID: 12788974

6. Dodds PN, Lawrence GJ, Catanzariti A-M, Teh T, Wang C-IA, Ayliffe MA, et al. Direct protein interaction underlies gene-for-gene specificity and coevolution of the flax resistance genes and flax rust avirulence genes. Proc Natl Acad Sci USA. 2006; 103: 8888-8893. https://doi.org/10.1073/pnas.0602577103 PMID: 16731621

7. Krasileva KV, Dahlbeck D, Staskawicz BJ. Activation of an Arabidopsis resistance protein is specified by the in planta association of its leucine-rich repeat domain with the cognate oomycete effector. Plant Cell. 2010; 22: 2444-2458. https://doi.org/10.1105/tpc.110.075358 PMID: 20601497

8. Van der Biezen EA, Jones JD. Plant disease-resistance proteins and the gene-for-gene concept. Trends Biochem Sci. 1998; 23: 454-456. https://doi.org/10.1016/s0968-0004(98)01311-5 PMID: 9868361

9. Hauck P, Thilmony R, He SY. A Pseudomonas syringae type III effector suppresses cell wall-based extracellular defense in susceptible Arabidopsis plants. Proc Natl Acad Sci USA. 2003; 100: 85778582. https://doi.org/10.1073/pnas.1431173100 PMID: 12817082

10. Glazebrook J. Contrasting mechanisms of defense against biotrophic and necrotrophic pathogens. Annu Rev Phytopathol. 2005; 43: 205-227. https://doi.org/10.1146/annurev.phyto.43.040204.135923 PMID: 16078883

11. Shi G, Zhang Z, Friesen TL, Raats D, Fahima T, Brueggeman RS, et al. The hijacking of a receptor kinase-driven pathway by a wheat fungal pathogen leads to disease. Sci Adv. 2016; 2: e1600822. https://doi.org/10.1126/sciadv.1600822 PMID: 27819043

12. Liu Z, Holmes DJ, Faris JD, Chao S, Brueggeman RS, Edwards MC, et al. Necrotrophic effector-trig gered susceptibility (NETS) underlies the barley-Pyrenophora teres $f$. teres interaction specific to chromosome 6H. Mol Plant Pathol. 2015; 16: 188-200. https://doi.org/10.1111/mpp.12172 PMID: 25040207

13. Friesen TL, Faris JD. Characterization of the wheat- Stagonospora nodorum disease system: what is the molecular basis of this quantitative necrotrophic disease interaction ${ }^{\dagger}$. Canadian Journal of Plant Pathology. 2010; 32: 20-28. https://doi.org/10.1080/07060661003620896 
14. Lorrain S, Vailleau F, Balagué C, Roby D. Lesion mimic mutants: keys for deciphering cell death and defense pathways in plants? Trends Plant Sci. 2003; 8: 263-271. https://doi.org/10.1016/S1360-1385 (03)00108-0 PMID: 12818660

15. Rostoks N, Schmierer D, Kudrna D, Kleinhofs A. Barley putative hypersensitive induced reaction genes: genetic mapping, sequence analyses and differential expression in disease lesion mimic mutants. Theor Appl Genet. 2003; 107: 1094-1101. https://doi.org/10.1007/s00122-003-1351-8 PMID: 12928776

16. Rostoks N, Schmierer D, Mudie S, Drader T, Brueggeman R, Caldwell DG, et al. Barley necrotic locus nec1 encodes the cyclic nucleotide-gated ion channel 4 homologous to the Arabidopsis HLM1. Mol Genet Genomics. 2006; 275: 159-168. https://doi.org/10.1007/s00438-005-0073-9 PMID: 16341885

17. Lundqvist U, Franckowiak JD, Konishi T. New and revised descriptions of barley genes. Barley genetics newsletter. 1997.

18. Balagué C, Lin B, Alcon C, Flottes G, Malmström S, Köhler C, et al. HLM1, an essential signaling component in the hypersensitive response, is a member of the cyclic nucleotide-gated channel ion channel family. Plant Cell. 2003; 15: 365-379. https://doi.org/10.1105/tpc.006999 PMID: 12566578

19. Stintzi A, Heitz T, Prasad V, Wiedemann-Merdinoglu S, Kauffmann S, Geoffroy P, et al. Plant "pathogenesis-related" proteins and their role in defense against pathogens. Biochimie. 1993; 75: 687-706. https://doi.org/10.1016/0300-9084(93)90100-7 PMID: 8286442

20. Lyngkjær MF, Carver TL. Conditioning of cellular defence responses to powdery mildew in cereal leaves by prior attack. Mol Plant Pathol. 2000; 1: 41-49. https://doi.org/10.1046/j.1364-3703.2000.00006.x PMID: 20572949

21. Kjaer $\mathrm{B}$, Jensen HP, Jensen J, Jorgensen JH. Associations between three ml-o powdery mildew resistance genes and agronomic traits in barley. Euphytica. 1990; 46: 185-193. https://doi.org/10.1007/ BF00027217

22. Kumar J, Schafer $P$, Huckelhoven R, Langen G, Baltruschat H, Stein E, et al. Bipolaris sorokiniana, a cereal pathogen of global concern: cytological and molecular approaches towards better control. Mol Plant Pathol. 2002; 3: 185-195. https://doi.org/10.1046/j.1364-3703.2002.00120.x PMID: 20569326

23. Jansen C, von Wettstein D, Schäfer W, Kogel K-H, Felk A, Maier FJ. Infection patterns in barley and wheat spikes inoculated with wild-type and trichodiene synthase gene disrupted Fusarium graminearum. Proc Natl Acad Sci USA. 2005; 102: 16892-16897. https://doi.org/10.1073/pnas.0508467102 PMID: 16263921

24. McGrann GRD, Stavrinides A, Russell J, Corbitt MM, Booth A, Chartrain L, et al. A trade off between mlo resistance to powdery mildew and increased susceptibility of barley to a newly important disease, Ramularia leaf spot. J Exp Bot. 2014; 65: 1025-1037. https://doi.org/10.1093/jxb/ert452 PMID: 24399175

25. Wolter M, Hollricher K, Salamini F, Schulze-Lefert $\mathrm{P}$. The mlo resistance alleles to powdery mildew infection in barley trigger a developmentally controlled defence mimic phenotype. Mol Gen Genet. 1993; 239: 122-128. https://doi.org/10.1007/BF00281610 PMID: 8510641

26. Fischbeck G, Hauser H. Cytogenetic studies of some induced barley mutants. Barley Genetics Newsletter. 1978. pp. 36-37.

27. Zhong S, Steffenson BJ. Identification and characterization of DNA markers associated with a locus conferring virulence on barley in the plant pathogenic fungus Cochliobolus sativus. Theor Appl Genet. 2002; 104: 1049-1054. https://doi.org/10.1007/s00122-001-0811-2 PMID: 12582611

28. Keisa A, Brueggeman R, Drader T, Kleinhofs A, Rostoks N. Transcriptome analysis of the barley nec3 mutant reveals a potential link with abiotic stress response related signaling pathways. Environ Exp Bot. 2010; 8: 1-16.

29. Fischbeck G, Hauser H. Research Notes. Barley Genetic Newsletter. (2). 1976. pp. 28-29.

30. Falk DE, Swartz MJ, Kasha KJ. Linkage data with genes near the centromere of barley chromosome 6 . Barley Genetics Newsletter. 1980.

31. Fujiwara T, Maisonneuve S, Isshiki M, Mizutani M, Chen L, Wong HL, et al. Sekiguchi lesion gene encodes a cytochrome P450 monooxygenase that catalyzes conversion of tryptamine to serotonin in rice. J Biol Chem. 2010; 285: 11308-11313. https://doi.org/10.1074/jbc.M109.091371 PMID: 20150424

32. Ishihara A, Hashimoto Y, Tanaka C, Dubouzet JG, Nakao T, Matsuda F, et al. The tryptophan pathway is involved in the defense responses of rice against pathogenic infection via serotonin production. Plant J. 2008; 54: 481-495. https://doi.org/10.1111/j.1365-313X.2008.03441.x PMID: 18266919

33. Mascher M, Muehlbauer GJ, Rokhsar DS, Chapman J, Schmutz J, Barry K, et al. Anchoring and ordering NGS contig assemblies by population sequencing (POPSEQ). Plant J. 2013; 76: 718-727. https:// doi.org/10.1111/tpj.12319 PMID: 23998490 
34. Monat C, Padmarasu S, Lux T, Wicker T, Gundlach H, Himmelbach A, et al. TRITEX: chromosomescale sequence assembly of Triticeae genomes with open-source tools. Genome Biol. 2019; 20: 284. https://doi.org/10.1186/s13059-019-1899-5 PMID: 31849336

35. Werck-Reichhart D, Feyereisen R. Cytochromes P450: a success story. Genome Biol. 2000; 1: REVIEWS3003. https://doi.org/10.1186/gb-2000-1-6-reviews3003 PMID: 11178272

36. Keisa A, Kanberga-Silina K, Nakurte I, Kunga L, Rostoks N. Differential disease resistance response in the barley necrotic mutant nec1. BMC Plant Biol. 2011; 11: 66. https://doi.org/10.1186/1471-2229-1166 PMID: 21496226

37. Acharya, Dutta K, Pradhan AK, Prakash. "Bipolaris sorokiniana" (Sacc.) Shoem.: The most destructive wheat fungal pathogen in the warmer areas. Australian Journal of Crop Science. 2011.

38. O'Connell RJ, Panstruga R. Tête à tête inside a plant cell: establishing compatibility between plants and biotrophic fungi and oomycetes. New Phytol. 2006; 171: 699-718. https://doi.org/10.1111/j.1469-8137. 2006.01829.x PMID: 16918543

39. Schmidt SM, Kuhn H, Micali C, Liller C, Kwaaitaal M, Panstruga R. Interaction of a Blumeria graminis $\mathrm{f}$. sp. hordei effector candidate with a barley ARF-GAP suggests that host vesicle trafficking is a fungal pathogenicity target. Mol Plant Pathol. 2014; 15: 535-549. https://doi.org/10.1111/mpp.12110 PMID: 24304971

40. Sels J, Mathys J, De Coninck BMA, Cammue BPA, De Bolle MFC. Plant pathogenesis-related (PR) proteins: a focus on PR peptides. Plant Physiol Biochem. 2008; 46: 941-950. https://doi.org/10.1016/j. plaphy.2008.06.011 PMID: 18674922

41. Solanki S, Ameen G, Borowicz P, Brueggeman RS. Shedding light on penetration of cereal host stomata by wheat stem rust using improved methodology. Sci Rep. 2019; 9: 7939. https://doi.org/10.1038/ s41598-019-44280-6 PMID: 31138873

42. Solanki S, Ameen G, Zhao J, Flaten J, Borowicz P, Brueggeman RS. Visualization of spatial gene expression in plants by modified RNAscope fluorescent in situ hybridization. Plant Methods. 2020; 16: 71. https://doi.org/10.1186/s13007-020-00614-4 PMID: 32467719

43. Nirmala J, Dahl S, Steffenson BJ, Kannangara CG, von Wettstein D, Chen X, et al. Proteolysis of the barley receptor-like protein kinase RPG1 by a proteasome pathway is correlated with Rpg1-mediated stem rust resistance. Proc Natl Acad Sci USA. 2007; 104: 10276-10281. https://doi.org/10.1073/pnas. 0703758104 PMID: 17548826

44. Nirmala J, Brueggeman R, Maier C, Clay C, Rostoks N, Kannangara CG, et al. Subcellular localization and functions of the barley stem rust resistance receptor-like serine/threonine-specific protein kinase Rpg1. Proc Natl Acad Sci USA. 2006; 103: 7518-7523. https://doi.org/10.1073/pnas.0602379103 PMID: 16648249

45. Solanki S. Dissecting the Mystery Behind the Rpg5 Mediated Puccinia graminis Resistance in Barley Using Genetics, Molecular and Bioinformatics Approaches. 2017.

46. Faris JD, Zhang Z, Lu H, Lu S, Reddy L, Cloutier S, et al. A unique wheat disease resistance-like gene governs effector-triggered susceptibility to necrotrophic pathogens. Proc Natl Acad Sci USA. 2010; 107: 13544-13549. https://doi.org/10.1073/pnas.1004090107 PMID: 20624958

47. Faris JD, Friesen TL. Plant genes hijacked by necrotrophic fungal pathogens. Curr Opin Plant Biol. 2020; 56: 74-80. https://doi.org/10.1016/j.pbi.2020.04.003 PMID: 32492572

48. Heil M, Land WG. Danger signals-damaged-self recognition across the tree of life. Front Plant Sci. 2014; 5: 578. https://doi.org/10.3389/fpls.2014.00578 PMID: 25400647

49. Graham SE, Peterson JA. How similar are P450s and what can their differences teach us? Arch Biochem Biophys. 1999; 369: 24-29. https://doi.org/10.1006/abbi.1999.1350 PMID: 10462437

50. Hamberger $B, B a k S$. Plant $P 450$ s as versatile drivers for evolution of species-specific chemical diversity. Philos Trans R Soc Lond B Biol Sci. 2013; 368: 20120426. https://doi.org/10.1098/rstb.2012.0426 PMID: 23297350

51. Shimizu T, Nakano T, Takamizawa D, Desaki Y, Ishii-Minami N, Nishizawa Y, et al. Two LysM receptor molecules, CEBiP and OsCERK1, cooperatively regulate chitin elicitor signaling in rice. Plant J. 2010; 64: 204-214. https://doi.org/10.1111/j.1365-313X.2010.04324.x PMID: 21070404

52. Schuler MA, Duan H, Bilgin M, Ali S. Arabidopsis cytochrome P450s through the looking glass: a window on plant biochemistry. Phytochem Rev. 2006; 5: 205-237. https://doi.org/10.1007/s11101-0069035-Z

53. Ameen G, Solanki S, Drader T, Sager-Bittara L, Steffenson B, Kleinhofs A, et al. rcs5- mediated spot blotch resistance in barley is conferred by wall-associated kinases that resist pathogen manipulation. BioRxiv. 2020. https://doi.org/10.1101/2020.04.13.040238 
54. Carollo V, Matthews DE, Lazo GR, Blake TK, Hummel DD, Lui N, et al. GrainGenes 2.0. an improved resource for the small-grains community. Plant Physiol. 2005; 139: 643-651. https://doi.org/10.1104/ pp.105.064485 PMID: 16219925

55. Blake VC, Birkett C, Matthews DE, Hane DL, Bradbury P, Jannink J-L. The Triticeae Toolbox: Combining Phenotype and Genotype Data to Advance Small-Grains Breeding. Plant Genome. 2016; 9. https:// doi.org/10.3835/plantgenome2014.12.0099 PMID: 27898834

56. Richards $\mathrm{J}$, Chao S, Friesen $\mathrm{T}$, Brueggeman R. Fine mapping of the barley chromosome $6 \mathrm{H}$ net form net blotch susceptibility locus. G3 (Bethesda). 2016; 6: 1809-1818. https://doi.org/10.1534/g3.116. 028902 PMID: 27172206

57. Solanki S, Richards J, Ameen G, Wang X, Khan A, Ali H, et al. Characterization of genes required for both Rpg1 and rpg4-mediated wheat stem rust resistance in barley. BMC Genomics. 2019; 20: 495. https://doi.org/10.1186/s12864-019-5858-z PMID: 31200635 